Rakenteiden Mekaniikka (Journal of Structural Mechanics)

Vol. 50, Nro 4, 2017, s. 376-404

http://rakenteidenmekaniikka.journal.fi/index

https:/doi.org/10.23998/rm.64856

CKirjoittaja(t) 2017.

Vapaasti saatavilla CC BY-SA 4.0 lisensioitu.

\title{
Taivutuksesta ja väännöstä, osa I: Teoria
}

\author{
Jukka Aalto
}

Tiivistelmä. Artikkelissa johdetaan kuormituksen alaiselle suoralle sauvalle yhdistetty taivutus- ja vääntöteoria. Jännityksille tehdään tyypilliset sauvateorian mukaiset otaksumat. Siirtymille käytetään otaksumaa, jossa tavanomaisia poikkileikkauksen jäykän kappaleen liikkeen mukaisia siirtymiä tarkennetaan aksiaalisen siirtymän osalta neljää käyristymisfunktiota käyttäen. Käyristymisfunktioiden määrittämiseksi poikkileikkauksen alueella johdetaan yksinkertaiset reuna-arvotehtävät, jotka voidaan ratkaista numeerisesti esimerkiksi elementtimenetelmällä. Yhdistetyn taivutuksen ja väännön yhtälöt johdetaan virtuaalisen työn periaatetta käyttäen. Kehitettyä teoriaa voidaan pitää avointen ohutseinämäisten sauvojen taivutus- ja vääntöteorian yleistyksenä. Se soveltuu kaiken tyyppisille, myös useasta materiaalista koostuville, poikkileikkauksille ja ottaa huomioon leikkausmuodonmuutoksen vaikutuksen taipumaan.

Avainsanat: sauvateoria, taivutus, vääntö, leikkausmuodonmuutos, käyristymisfunktio, reunaarvotehtävä, heikko muoto, elementtimenetelmä

Vastaanotettu 29.5.2017. Hyväksytty 24.6.2017. Julkaistu verkossa 14.12.2017.

\section{Johdanto}

Tässä artikkelissa esitetään perusteellisesti taivutus- ja vääntöteoria, jota kirjoittaja on aiemmin käsitellyt konferenssiartikkeleissa [1] ja [2]. Tilan puutteen vuoksi artikkeliin ei sisälly sovelluksia eikä esimerkkejä. Kirjoittajan on tarkoitus käsitellä näitä aiheita myöhemmin tässä lehdessä.

\subsection{Otaksumia ja yhtälöitä}

Tarkastellaan suoraa tasapaksua poikkileikkaukseltaan muuttumatonta sauvaa, jonka poikkileikkauksen pisteeseen on asetettu $x, y, z$-koordinaatisto siten, että $x$-akseli on palkin pituussuuntainen ja $y, z-$ taso on poikkileikkaustason suuntainen. Tarkastelussa sovelletaan tavanomaisia sauvateorian jännityksiä koskevia otaksumia

$$
\sigma_{y}=\sigma_{z}=\tau_{y z}=0 .
$$

Jatkossa tarvittavat muodonmuutosten ja siirtymien yhteydet ovat 


$$
\varepsilon_{x}=\frac{\partial u_{x}}{\partial x}, \quad \gamma_{y x}=\frac{\partial u_{x}}{\partial y}+\frac{\partial u_{y}}{\partial x}, \quad \gamma_{z x}=\frac{\partial u_{x}}{\partial z}+\frac{\partial u_{z}}{\partial x}
$$

ja jännitysotaksumia (1) vastaava Hooken laki saa muodon

$$
\sigma_{x}=E \varepsilon_{x}, \quad \tau_{y x}=G \gamma_{y x}, \quad \tau_{z x}=G \gamma_{z x} .
$$

Lisäksi tarvitaan sauvan yleisen pisteen differentiaalipalan tasapainoyhtälöitä (ilman massavoimia), jotka ovat jännitysotaksumien (1) vallitessa muotoa

$$
\frac{\partial \sigma_{x}}{\partial x}+\frac{\partial \tau_{y x}}{\partial y}+\frac{\partial \tau_{z x}}{\partial z}=0, \quad \frac{\partial \tau_{y x}}{\partial x}=0, \quad \frac{\partial \tau_{z x}}{\partial x}=0
$$

ja niitä vastaavia reunaehtoyhtälöitä palkin (kuormittamattomalla) sylinterimäisellä pitkittäisreunalla $\left(n_{x}=0\right)$, joista ensimmäinen on

$$
n_{y} \tau_{y x}+n_{z} \tau_{z x}=0
$$

ja kaksi muuta toteutuvat jännitysotaksumien (1) vallitessa automaattisesti.

\subsection{Siirtymäotaksumat}

Otaksutaan aluksi, että poikkileikkauksen siirtymä on jäykän kappaleen pienen liikkeen mukainen, jolloin "tasot pysyvät tasoina”. Siirtopisteeksi poikkileikkauksen jäykän kappaleen liikkeessä otetaan tietty piste $\mathrm{T}$, jota kutsutaan vääntökeskiöksi ja jonka sijainti valitaan jatkossa fysikaalisesti mielekkäällä tavalla. Siirtymäkomponenttien kinemaattiset lausekkeet ovat tällöin (liite A)

$$
\begin{aligned}
& u_{x}^{\mathrm{R}}(x, y, z)=u_{\mathrm{T}}(x)-\theta_{z}(x)\left(y-y_{\mathrm{T}}\right)-\theta_{y}(x)\left(z-z_{\mathrm{T}}\right), \\
& u_{y}^{\mathrm{R}}(x, y, z)=v_{\mathrm{T}}(x)-\theta_{x}(x)\left(z-z_{\mathrm{T}}\right), \\
& u_{z}^{\mathrm{R}}(x, y, z)=w_{\mathrm{T}}(x)+\theta_{x}(x)\left(y-y_{\mathrm{T}}\right) .
\end{aligned}
$$

Suuret $u_{\mathrm{T}}, \quad v_{\mathrm{T}}$ ja $w_{\mathrm{T}}$ ovat vääntökeskiön siirtymäkomponentit ja $\theta_{x}, \theta_{y}$ ja $\theta_{z}$ poikkileikkauksen (käsitettynä äärettömän ohueksi jäykäksi levyksi) pienet rotaatiot. Yläindeksi R viittaa tässä jäykän kappaleen (engl. rigid body) liikkeeseen. Lausekkeissa (6) osoittautuu tarkoituksenmukaiseksi käyttää vääntökeskiön $\mathrm{T}$ aksiaalisen siirtymän $u_{\mathrm{T}}$ sijasta poikkileikkauksen origon $\mathrm{O}$ aksiaalista siirtymää $u_{0}$. Näiden välillä on yhteys

$$
u_{\mathrm{T}}=u_{\mathrm{O}}-\theta_{\mathrm{z}} y_{\mathrm{T}}-\theta_{y} z_{\mathrm{T}} \text {. }
$$

Kun vielä merkitään $u_{\mathrm{O}}=u, v_{\mathrm{T}}=v$ ja $w_{\mathrm{T}}=w$, siirtymäkomponenteille saadaan esitys

$$
\begin{aligned}
& u_{x}^{\mathrm{R}}(x, y, z)=u(x)-\theta_{z}(x) y-\theta_{y}(x) z, \\
& u_{y}^{\mathrm{R}}(x, y, z)=v(x)-\theta_{x}(x)\left(z-z_{\mathrm{T}}\right), \\
& u_{z}^{\mathrm{R}}(x, y, z)=w(x)+\theta_{x}(x)\left(y-y_{\mathrm{T}}\right) .
\end{aligned}
$$

Tunnetusti "tasot pysyvät tasoina” mukainen otaksuma ei johda tyydyttävään tulokseen erityisesti väännön suhteen. Parannetaan siirtymäapproksimaatiota (8) sallimalla poikkileikkauksen käyristyä. Siirtymäapproksimaation tarkennettu muoto on nyt

$$
\begin{aligned}
& u_{x}(x, y, z)=u_{x}^{\mathrm{R}}(x, y, z)+\Delta u_{x}(x, y, z), \\
& u_{y}(x, y, z)=u_{y}^{\mathrm{R}}(x, y, z), \\
& u_{z}(x, y, z)=u_{z}^{\mathrm{R}}(x, y, z) .
\end{aligned}
$$

Toisin sanoen jäykän kappaleen liikkeen mukaista approksimaatiota korjataan pelkistetysti vain komponentin $u_{x}$ osalta. Tässä artikkelissa lisäsiirtymälle käytetään esitystä 


$$
\Delta u_{x}(x, y, z)=\theta_{x}^{\prime}(x) \phi(y, z)+\theta_{x}^{\prime \prime \prime}(x) \psi_{x}(y, z)-\theta_{z}^{\prime \prime}(x) \psi_{y}(y, z)-\theta_{y}^{\prime \prime}(x) \psi_{z}(y, z),
$$

missä funktioita $\phi(y, z), \psi_{x}(y, z), \psi_{y}(y, z)$ ja $\psi_{z}(y, z)$ kutsutaan käyristymisfunktioiksi ja yläpilkku merkitsee derivointia $x$ :n suhteen. Esitystä (10) ei tässä yhteydessä tarkemmin perustella, mutta se osoittautuu tarkoituksenmukaisiksi. Kuitenkin voidaan todeta, että lausekkeen (10) ensimmäinen termi $\theta_{x}^{\prime}(x) \phi(y, z)$ on muotoa, joka on käytössä Saint-Venantin vääntöteoriassa ([3] s. 293). Muut termit ovat sikäli saman tyyppisiä, että niissä rotaatiokomponenttien "aksiaalisia derivaattoja” kertoo poikkileikkauksen koordinaattien y ja $z$ funktio.

\subsection{Paikalliset otaksumat}

Suoritettaessa tiettyyn poikkileikkaukseen liittyviä paikallisia tarkasteluja otaksutaan, että palkin jännitysresultanttien tasapainoyhtälöissä (kaavat (44)) voidaan jakautunut kuormitus (kuormitukset $q_{x}(x), q_{y}(x), q_{z}(x)$, momenttikuormitukset $\left.m_{x}(x), m_{y}(x), m_{z}(x)\right)$ ja niin kutsuttu käyristymismomenttikuormitus $b(x)$, jotka on määritelty kaavoilla (40)) jättää huomiotta. Näin esimerkiksi tasapainoyhtälöiden (44b) ja (44c) sijasta paikallisessa tarkastelussa voidaan käyttää yhtälöitä $Q_{y}=M_{z}^{\prime}$ ja $Q_{z}=M_{y}^{\prime}$. Edelleen otaksutaan, että paikallisesti tarkasteltavan poikkileikkauksen ympäristössä siirtymäapproksimaatioon liittyvät, pelkästään aksiaalisesta koordinaatista $x$ riippuvat suureet $u(x), v(x), w(x), \theta_{x}(x)$, $\theta_{y}(x)$ ja $\theta_{z}(x)$, voidaan korvata niiden sopivaa astelukua olevilla polynomiapproksimaatioilla. Näin paikallisesti aksiaalinen siirtymä $u(x)$ on lineaarinen, poikittaiset siirtymät $v(x)$ ja $w(x)$ kuubisia, vääntökulma $\theta_{x}(x)$ kuubinen sekä rotaatiot $\theta_{y}(x)$ ja $\theta_{z}(x)$ kvadraattisia polynomeja. Valittuja astelukuja perustellaan luvussa 5. Tämän vuoksi tiettyyn poikki-leikkaukseen liittyvissä paikallisissa tarkasteluissa näiden funktioiden derivaatoille voidaan kirjoittaa

$$
u^{\prime \prime}(x)=0, v^{(4)}(x)=0, w^{(4)}(x)=0, \theta_{x}^{(4)}(x)=0, \theta_{y}^{\prime \prime \prime}(x)=0, \theta_{z}^{\prime \prime \prime}(x)=0 .
$$

Näitä korkeammat derivaatat luonnollisesti häviävät. Tehdyt paikalliset otaksumat voivat tuntua melko mielivaltaisilta. Niiden tarkoituksena on kuitenkin vain synnyttää tyydyttävät edellytykset alunperin tuntemattomien funktioiden $\phi, \psi_{x}, \psi_{y}$ ja $\psi_{z}$ määrittämiseksi. Eihän nämä funktiot sisältävä suure $\Delta u_{x}$ ole myöskään muuta kuin puoli-intuitiivisesti valittu sopivalta tuntuva aksiaalinen siirtymätarkennus.

\section{Käyristymisfunktioiden määrittäminen}

\subsection{Siirtymät}

Seuraavassa johdetaan reuna-arvotehtävät poikkileikkauksen käyristymisfunktioiden määrittämiseksi. Tarkastelu tapahtuu nyt tietyssä poikkileikkauksessa, joten edellämainitut paikalliset otaksumat ovat voimassa. Tarkastelussa sovelletaan lisäsiirtymän lauseketta (10). Siirtymäkomponenttien lausekkeet (9) lopullisessa muodossaan ovat siis

$$
\begin{aligned}
& u_{x}(x, y, z)=u(x)-\theta_{z}(x) y-\theta_{y}(x) z \\
& +\theta_{x}^{\prime}(x) \phi(y, z)+\theta_{x}^{\prime \prime \prime}(x) \psi_{x}(y, z)-\theta_{z}^{\prime \prime}(x) \psi_{y}(y, z)-\theta_{y}^{\prime \prime}(x) \psi_{z}(y, z), \\
& u_{y}(x, y, z)=v(x)-\theta_{x}(x)\left(z-z_{\mathrm{T}}\right) \text {, } \\
& u_{z}(x, y, z)=w(x)+\theta_{x}(x)\left(y-y_{\mathrm{T}}\right) \text {. }
\end{aligned}
$$




\subsection{Muodonmuutokset ja jännitykset}

Muodonmuutoskomponenteille (2) saadaan käyttäen lausekkeita (12) ja ottamalla huomioon kaavat (11) lausekkeet

$$
\begin{aligned}
& \varepsilon_{x}=u^{\prime}-\theta_{z}^{\prime} y-\theta_{y}^{\prime} z+\theta_{x}^{\prime \prime} \phi, \\
& \gamma_{y x}=\theta_{x}^{\prime}\left(\frac{\partial \phi}{\partial y}-z+z_{\mathrm{T}}\right)+\theta_{x}^{\prime \prime \prime} \frac{\partial \psi_{x}}{\partial y}+\gamma_{y}-\theta_{z}^{\prime \prime} \frac{\partial \psi_{y}}{\partial y}-\theta_{y}^{\prime \prime} \frac{\partial \psi_{z}}{\partial y}, \\
& \gamma_{z x}=\theta_{x}^{\prime}\left(\frac{\partial \phi}{\partial z}+y-y_{\mathrm{T}}\right)+\theta_{x}^{\prime \prime \prime} \frac{\partial \psi_{x}}{\partial z}+\gamma_{z}-\theta_{z}^{\prime \prime} \frac{\partial \psi_{y}}{\partial z}-\theta_{y}^{\prime \prime} \frac{\partial \psi_{z}}{\partial z},
\end{aligned}
$$

missä on otettu käyttöön merkinnät

$$
\gamma_{y}=v^{\prime}-\theta_{z}, \quad \gamma_{z}=w^{\prime}-\theta_{y} .
$$

Suureita $\gamma_{y}$ ja $\gamma_{z}$ kutsutaan keskimääräisiksi liukumiksi.

Otetaan käyttöön uudet muunnetut käyristymisfunktiot $\Phi(y, z), \Psi_{x}(y, z), \Psi_{y}(y, z)$ ja $\Psi_{z}(y, z)$, jotka pyritään määrittämään siten, että muodonmuutokset (13) saadaan muotoon

$$
\begin{aligned}
& \varepsilon_{x}=u^{\prime}-\theta_{z}^{\prime} y-\theta_{y}^{\prime} z+\theta_{x}^{\prime \prime} \phi, \\
& \gamma_{y x}=\theta_{x}^{\prime}\left(\frac{\partial \Phi}{\partial y}-z\right)+\theta_{x}^{\prime \prime \prime} \frac{\partial \Psi_{x}}{\partial y}-\theta_{z}^{\prime \prime} \frac{\partial \Psi_{y}}{\partial y}-\theta_{y}^{\prime \prime} \frac{\partial \Psi_{z}}{\partial y}, \\
& \gamma_{z x}=\theta_{x}^{\prime}\left(\frac{\partial \Phi}{\partial z}+y\right)+\theta_{x}^{\prime \prime \prime} \frac{\partial \Psi_{x}}{\partial z}-\theta_{z}^{\prime \prime} \frac{\partial \Psi_{y}}{\partial z}-\theta_{y}^{\prime \prime} \frac{\partial \Psi_{z}}{\partial z} .
\end{aligned}
$$

Näissä lausekkeissa venymän $\varepsilon_{x}$ lauseke on säilytetty ennallaan, mutta liukumien $\gamma_{x y}$ ja $\gamma_{x z}$ lausekkeet ovat jatkotarkastelua silmälläpitäen huomattavasti yksinkertaisemmat. Niistä puuttuvat vääntökeskiön koordinaatit $y_{\mathrm{T}}$ ja $z_{\mathrm{T}}$ sekä keskimääräiset liukumat $\gamma_{y}$ ja $\gamma_{z}$. Vertaamalla liukumien lausekkeita (13) ja (15) liitteessä B on osoitettu, että alkuperäisillä käyristymisfunktioilla $\phi, \psi_{x}, \psi_{y}, \psi_{z}$ ja muunnetuilla käyristymisfunktiolla $\Phi, \Psi_{x}, \Psi_{y}, \Psi_{z}$ on seuraavat yhteydet

$$
\begin{aligned}
& \phi(y, z)=\Phi(y, z)+\Delta_{\Phi}-z_{T} y+y_{\mathrm{T}} z, \\
& \psi_{x}(y, z)=\Psi_{x}(y, z)+\Delta_{\Psi_{x}}, \\
& \psi_{y}(y, z)=\Psi_{y}(y, z)+\Delta_{\Psi_{y}}-c_{11} y-c_{21} z, \\
& \psi_{z}(y, z)=\Psi_{z}(y, z)+\Delta_{\Psi_{z}}-c_{12} y-c_{22} z,
\end{aligned}
$$

missä $\Delta_{\Phi}, \Delta_{\Psi_{x}}, \Delta_{\Psi_{y}}, \Delta_{\Psi_{z}}, c_{11}, c_{12}, c_{21}$ ja $c_{22}$ ovat vakioita. Vakiot $\Delta_{\Phi}, \Delta_{\Psi_{x}}, \Delta_{\Psi_{y}}$ ja $\Delta_{\Psi_{z}}$ ilmaisevat alkuperäisten ja muunnettujen käyristymisfunktioiden arvojen erotukset origon kohdalla (mikäli origo sijaitsee poikkileikkauksen alueella). Liitteessä C on osoitettu, että keskimääräisillä liukumilla $\gamma_{y}, \gamma_{z}$ ja kiertymien toisilla derivaatoilla $\theta_{y}^{\prime \prime}, \theta_{z}^{\prime \prime}$ on lineaariset yhteydet

$$
\left\{\begin{array}{l}
\gamma_{y} \\
\gamma_{z}
\end{array}\right\}=-\left[\begin{array}{ll}
c_{11} & c_{12} \\
c_{21} & c_{22}
\end{array}\right]\left\{\begin{array}{l}
\theta_{z}^{\prime \prime} \\
\theta_{y}^{\prime \prime}
\end{array}\right\},
$$

ja esitetty kaava (C.3), jolla vakiot $C_{11}, C_{12}, C_{21}$ ja $C_{22}$ voidaan määrittää.

Jännityskomponenteille saadaan Hooken lain (3) ja muodonmuutosten lausekkeiden (15) avulla siis lausekkeet 


$$
\begin{aligned}
& \sigma_{x}=E\left(u^{\prime}-\theta_{z}^{\prime} y-\theta_{y}^{\prime} z+\theta_{x}^{\prime \prime} \phi\right), \\
& \tau_{y x}=G\left[\theta_{x}^{\prime}\left(\frac{\partial \Phi}{\partial y}-z\right)+\theta_{x}^{\prime \prime \prime} \frac{\partial \Psi_{x}}{\partial y}-\theta_{z}^{\prime \prime} \frac{\partial \Psi_{y}}{\partial y}-\theta_{y}^{\prime \prime} \frac{\partial \Psi_{z}}{\partial y}\right], \\
& \tau_{z x}=G\left[\theta_{x}^{\prime}\left(\frac{\partial \Phi}{\partial z}+y\right)+\theta_{x}^{\prime \prime \prime} \frac{\partial \Psi_{x}}{\partial z}-\theta_{z}^{\prime \prime} \frac{\partial \Psi_{y}}{\partial z}-\theta_{y}^{\prime \prime} \frac{\partial \Psi_{z}}{\partial z}\right] .
\end{aligned}
$$

\subsection{Reuna-arvotehtävät käyristymisfunktioille}

Sijoittamalla lausekkeet (18) jännityskomponenttien aksiaaliseen tasapainoyhtälöön (4a) ja vastaavaan reunaehtoyhtälöön (5) saadaan yhtälöt

$$
\begin{aligned}
& \theta_{x}^{\prime}\left\{\frac{\partial}{\partial y}\left[G\left(\frac{\partial \Phi}{\partial y}-z\right)\right]+\frac{\partial}{\partial z}\left[G\left(\frac{\partial \Phi}{\partial z}+y\right)\right]\right\}+\theta_{x}^{\prime \prime \prime}\left[\frac{\partial}{\partial y}\left(G \frac{\partial \Psi_{x}}{\partial y}\right)+\frac{\partial}{\partial z}\left(G \frac{\partial \Psi_{x}}{\partial z}\right)+E \phi\right] \\
& -\theta_{y}^{\prime \prime}\left[\frac{\partial}{\partial y}\left(G \frac{\partial \Psi_{z}}{\partial y}\right)+\frac{\partial}{\partial z}\left(G \frac{\partial \Psi_{z}}{\partial z}\right)+E z\right]-\theta_{z}^{\prime \prime}\left[\frac{\partial}{\partial y}\left(G \frac{\partial \Psi_{y}}{\partial y}\right)+\frac{\partial}{\partial z}\left(G \frac{\partial \Psi_{y}}{\partial z}\right)+E y\right]=0,
\end{aligned}
$$

ja

$$
\begin{aligned}
& \theta_{x}^{\prime}\left[n_{y} G\left(\frac{\partial \Phi}{\partial y}-z\right)+n_{z} G\left(\frac{\partial \Phi}{\partial z}+y\right)\right]+\theta_{x}^{\prime \prime \prime}\left(n_{y} G \frac{\partial \Psi_{x}}{\partial y}+n_{z} G \frac{\partial \Psi_{x}}{\partial z}\right) \\
& -\theta_{y}^{\prime \prime}\left(n_{y} G \frac{\partial \Psi_{z}}{\partial y}+n_{z} G \frac{\partial \Psi_{z}}{\partial z}\right)-\theta_{z}^{\prime \prime}\left(n_{y} G \frac{\partial \Psi_{y}}{\partial y}+n_{z} G \frac{\partial \Psi_{y}}{\partial z}\right)=0 .
\end{aligned}
$$

Sauvaan kohdistuvat mahdolliset kuormitukset aiheuttavat erilaisia arvoja suureille $\theta_{x}^{\prime}, \theta_{x}^{\prime \prime \prime}, \theta_{y}^{\prime \prime}$ ja $\theta_{z}^{\prime \prime}$. Jotta yhtälöt (19) ja (20) toteutuisivat kaikilla mahdollisilla kuormituksilla, tulee niiden olla voimassa erikseen kaikilla arvoilla $\theta_{x}^{\prime}, \theta_{x}^{\prime \prime \prime}, \theta_{y}^{\prime \prime}$ ja $\theta_{z}^{\prime \prime}$. Tällä perusteella saadaan käyristymisfunktioille seuraavat reuna-arvotehtävät

$$
\begin{aligned}
& \frac{\partial}{\partial y}\left[G\left(\frac{\partial \Phi}{\partial y}-z\right)\right]+\frac{\partial}{\partial z}\left[G\left(\frac{\partial \Phi}{\partial z}+y\right)\right]=0 \text { A:ssa, } \\
& n_{y} G\left(\frac{\partial \Phi}{\partial y}-z\right)+n_{z} G\left(\frac{\partial \Phi}{\partial z}+y\right)=0 \text { s: llä, } \\
& \frac{\partial}{\partial y}\left(G \frac{\partial \Psi_{x}}{\partial y}\right)+\frac{\partial}{\partial z}\left(G \frac{\partial \Psi_{x}}{\partial z}\right)+E \phi=0 \text { A: ssa, } \\
& n_{y} G \frac{\partial \Psi_{x}}{\partial y}+n_{z} G \frac{\partial \Psi_{x}}{\partial z}=0 s: \text { llä, } \\
& \frac{\partial}{\partial y}\left(G \frac{\partial \Psi_{y}}{\partial y}\right)+\frac{\partial}{\partial z}\left(G \frac{\partial \Psi_{y}}{\partial z}\right)+E y=0 A: \text { ssa, } \\
& n_{y} G \frac{\partial \Psi_{y}}{\partial y}+n_{z} G \frac{\partial \Psi_{y}}{\partial z}=0 s: l l a ̈, \\
& \frac{\partial}{\partial y}\left(G \frac{\partial \Psi_{z}}{\partial y}\right)+\frac{\partial}{\partial z}\left(G \frac{\partial \Psi_{z}}{\partial z}\right)+E z=0 A: \text { ssa, } \\
& n_{y} G \frac{\partial \Psi_{z}}{\partial y}+n_{z} G \frac{\partial \Psi_{z}}{\partial z}=0 s: l l a ̈,
\end{aligned}
$$


missä $A$ on poikkipinnan alue ja s sen reuna. Koska reuna-arvoprobleemissa (21) esiintyy vain tuntemattoman funktion derivaattoja, mutta ei itse funktiota, niiden ratkaisufunktiot ovat vakiota vailla yksikäsitteisiä. Yksikäsitteisiksi käyristymisfunktiot saadaan vaatimalla niiden häviävän valitussa poikkipinnan pisteessä $\mathrm{P}_{0}$, jolle käytetään tässä nimitystä nollapiste. Ratkaistaessa reuna-arvoprobleemia (21) numeerisesti nollapisteeksi on luontevaa ottaa elementtiverkon solmu. Voidaan osoittaa, että nollapisteen valinta ei vaikuta esitettävällä teorialla saataviin tuloksiin. Probleemilla (21a) ja (21b) on heikko kytkentä, koska funktio $\phi$ riippuu funktiosta $\Phi$. Jos tehtävä (21a) ratkaistaan ensin, voidaan vakio $\Delta_{\Phi}$ ja vääntökeskiön koordinaatit $y_{\mathrm{T}}$ ja $z_{\mathrm{T}}$ laskea kaavalla (53). Sen jälkeen saadaan funktio $\phi$ määritetyksi kaavalla (16a). Kun se on tunnettu, reuna-arvotehtävä (21b) voidaan ratkaista.

\subsection{Reuna-arvoprobleemien heikot muodot}

Reuna-arvoprobleemien (21) numeerista ratkaisua formuloitaessa tarvitaan niiden heikkoja muotoja. Niistä on myös apua johdettaessa joitakin tämän artikkelin tuloksia. Liitteessä D on johdettu reuna-arvoprobleemien (21) heikot muodot. Ne ovat

$$
\begin{gathered}
\int_{A} G\left[\frac{\partial \hat{\Phi}}{\partial y}\left(\frac{\partial \Phi}{\partial y}-z\right)+\frac{\partial \hat{\Phi}}{\partial z}\left(\frac{\partial \Phi}{\partial z}+y\right)\right] \mathrm{d} A=0, \\
\int_{A} G\left(\frac{\partial \hat{\Psi}_{x}}{\partial y} \frac{\partial \Psi_{x}}{\partial y}+\frac{\partial \hat{\Psi}_{x}}{\partial z} \frac{\partial \Psi_{x}}{\partial z}\right) \mathrm{d} A=\int_{A} E \hat{\Psi}_{x} \phi \mathrm{d} A, \\
\int_{A} G\left(\frac{\partial \hat{\Psi}_{y}}{\partial y} \frac{\partial \Psi_{y}}{\partial y}+\frac{\partial \hat{\Psi}_{y}}{\partial z} \frac{\partial \Psi_{y}}{\partial z}\right) \mathrm{d} A=\int_{A} E \hat{\Psi}_{y} y \mathrm{~d} A, \\
\int_{A} G\left(\frac{\partial \hat{\Psi}_{z}}{\partial y} \frac{\partial \Psi_{z}}{\partial y}+\frac{\partial \hat{\Psi}_{z}}{\partial z} \frac{\partial \Psi_{z}}{\partial z}\right) \mathrm{d} A=\int_{A} E \hat{\Psi}_{z} z \mathrm{~d} A .
\end{gathered}
$$

Näissä yhtälöissä $\hat{\Phi}(y, z), \hat{\Psi}_{x}(y, z), \hat{\Psi}_{y}(y, z)$ ja $\hat{\Psi}_{z}(y, z)$ ovat mielivaltaisia testifunktioita.

\subsection{Poikittaisen tasapainon toteutuminen}

Sijoittamalla lausekkeet (18b) ja (18c) jännityskomponenttien poikittaisten tasapainoyhtälöiden (4b) ja (4c) vasempiin puoliin ja ottamalla huomioon yhteydet (11) saadaan

$$
\begin{aligned}
& \frac{\partial \tau_{y x}}{\partial x}=G \theta_{x}^{\prime \prime}\left(\frac{\partial \Phi}{\partial y}-z\right), \\
& \frac{\partial \tau_{z x}}{\partial x}=G \theta_{x}^{\prime \prime}\left(\frac{\partial \Phi}{\partial z}+y\right) .
\end{aligned}
$$

Havaitaan, että nämä tasapainoyhtälöt eivät toteudu. Niiden voidaan kyllä osoittaa toteutuvan koko poikkileikkauksessa keskimäärin. Integroimalla poikkipinnan yli saadaan

$$
\begin{aligned}
& \int_{A} \frac{\partial \tau_{y x}}{\partial x} d A=\theta_{x}^{\prime \prime} \int_{A} G\left(\frac{\partial \Phi}{\partial y}-z\right) d A=0 \\
& \int_{A} \frac{\partial \tau_{z x}}{\partial x} d A=\theta_{x}^{\prime \prime} \int_{A} G\left(\frac{\partial \Phi}{\partial z}+y\right) d A=0 .
\end{aligned}
$$

Viimeinen yhtäsuuruus saatiin soveltamalla heikkoa muotoa (22a), kun $\hat{\Phi}=y$ ja kun $\hat{\Phi}=z$. Todetaan, että tarkasteltavassa formulaatiossa jännityskomponenttien aksiaalinen tasapaino- 
yhtälö (4a) toteutuu poikkileikkauksen kaikissa pisteissä, mutta poikittaiset tasapainoyhtälöt (4b) ja (4c) toteutuvat vain keskimäärin.

\section{Jännitysresultantit ja niiden tasapainoyhtälöt}

\subsection{Reuna-arvotehtävät sauvan siirtymille ja kiertymille}

Jotta kaavoja (18) voitaisiin soveltaa tietyn poikkileikkauksen jännitysjakautumien määrittämiseksi, täytyy tuntea käyristymisfunktioiden $\Phi(y, z), \quad \Psi_{x}(y, z), \quad \Psi_{y}(y, z)$ ja $\Psi_{z}(y, z)$ lisäksi myös suureiden $u^{\prime}, \theta_{x}^{\prime}, \theta_{x}^{\prime \prime}, \theta_{x}^{\prime \prime \prime}, \theta_{y}^{\prime}, \theta_{y}^{\prime \prime}, \theta_{z}^{\prime}$ ja $\theta_{z}^{\prime \prime}$ arvot poikkileikkauksen kohdalla. Tämä on mahdollista ainoastaan, jos kyetään formuloimaan palkin alueelle $x_{1}<x<x_{2}$ reuna-arvotehtävät, joiden avulla palkin pituuskoordinaatista $x$ riippuvat funktiot: akselin siirtymä $u(x)$, vääntökeskiön siirtymät $v(x)$ ja $w(x)$ sekä poikkileikkauksen kiertymät $\theta_{x}(x), \theta_{y}(x)$ ja $\theta_{z}(x)$ voidaan määrittää. Sauvateorioille tyypillisesti tulee määritellä sopiva määrä jännitysresultantteja ja niitä vastaavia yleistettyjä muodonmuutoksia, jännitysresultanttien tasapainoyhtälöt sekä jännitysresultanttien ja yleistettyjen muodonmuutosten väliset yhteydet.

\subsection{Jännitysresultantit ja niiden tasapainoyhtälöt}

Aluksi määritetään jännitysresultantit ja niiden tasapainoyhtälöt. Sovelletaan virtuaalisen työn periaatetta, jossa virtuaalinen siirtymätila valitaan kaavojen (9) mukaisesesti. Virtuaalisen aksiaalisen siirtymän lisätermiksi ei kuitenkaan oteta koko lauseketta (10), vaan siihen sisällyteään vain sen ensimmäinen termi. Virtuaaliset siirtymät ovat

$$
\begin{aligned}
& \delta u_{x}=\delta u(x)-\delta \theta_{z}(x) y-\delta \theta_{y}(x) z+\delta \theta_{x}^{\prime} \phi(y, z), \\
& \delta u_{y}=\delta v-\delta \theta_{x}\left(z-z_{\mathrm{T}}\right), \\
& \delta u_{z}=\delta w+\delta \theta_{x}\left(y-y_{\mathrm{T}}\right) .
\end{aligned}
$$

Jatkossa osoittautuu, että tämä Saint-Venant henkinen esitys virtuaalisille siirtymille johtaa tarkoituksenmukaiseen lopputulokseen. Vastaavat virtuaaliset muodonmuutokset ovat

$$
\begin{aligned}
& \delta \varepsilon_{x}=\delta u^{\prime}-\delta \theta_{z}^{\prime} y-\delta \theta_{y}^{\prime} z+\delta \theta_{x}^{\prime \prime} \phi, \\
& \delta \gamma_{y x}=\delta \gamma_{y}+\delta \theta_{x}^{\prime}\left(\frac{\partial \Phi}{\partial y}-z\right), \\
& \delta \gamma_{z x}=\delta \gamma_{z}+\delta \theta_{x}^{\prime}\left(\frac{\partial \Phi}{\partial z}+y\right) .
\end{aligned}
$$

Palkin sisäisen virtuaalisen työn lauseke on

$$
\delta W_{\text {int }}=-\int_{x_{1}}^{x_{2}}\left[\int_{A}\left(\delta \varepsilon_{x} \sigma_{x}+\delta \gamma_{y x} \tau_{y x}+\delta \gamma_{z x} \tau_{z x}\right) \mathrm{d} A\right] \mathrm{d} x .
$$

Saadaan aluksi

$$
\begin{aligned}
\delta W_{\text {int }}= & -\int_{x_{1}}^{x_{2}}\left\{\delta u^{\prime} \int_{A} \sigma_{x} \mathrm{~d} A-\delta \theta_{z}^{\prime} \int_{A} \sigma_{x} y \mathrm{~d} A-\delta \theta_{y}^{\prime} \int_{A} \sigma_{x} z \mathrm{~d} A+\delta \theta_{x}^{\prime \prime} \int_{A} \sigma_{x} \phi \mathrm{d} A\right. \\
& \left.+\delta \gamma_{y} \int_{A} \tau_{y x} \mathrm{~d} A+\delta \gamma_{z} \int_{A} \tau_{z x} \mathrm{~d} A+\delta \theta_{x}^{\prime} \int_{A}\left[\left(\frac{\partial \Phi}{\partial y}-z\right) \tau_{y x}+\left(\frac{\partial \Phi}{\partial z}+y\right) \tau_{z x}\right] \mathrm{d} A\right\} \mathrm{d} x .
\end{aligned}
$$


Muokataan viimeistä integraalia. Sovelletaan ensin yhteyttä (16a):

$$
\begin{aligned}
& \int_{A}\left[\left(\frac{\partial \Phi}{\partial y}-z\right) \tau_{y x}+\left(\frac{\partial \Phi}{\partial z}+y\right) \tau_{z x}\right] \mathrm{d} A \equiv a \\
& =\int_{A}\left(\frac{\partial \phi}{\partial y} \tau_{y x}+\frac{\partial \phi}{\partial z} \tau_{z x}\right) \mathrm{d} A+\int_{A}\left[-\tau_{y x}\left(z-z_{\mathrm{T}}\right)+\tau_{z x}\left(y-y_{\mathrm{T}}\right)\right] \mathrm{d} A,
\end{aligned}
$$

sitten osittaisintegrointia:

$$
a=\int_{s} \phi\left(n_{y} \tau_{y x}+n_{z} \tau_{z x}\right) \mathrm{d} s-\int_{A} \phi\left(\frac{\partial \tau_{y x}}{\partial y}+\frac{\partial \tau_{z x}}{\partial z}\right) \mathrm{d} A+\int_{A}\left[-\tau_{y x}\left(z-z_{\mathrm{T}}\right)+\tau_{z x}\left(y-y_{\mathrm{T}}\right)\right] \mathrm{d} A
$$

ja lopuksi tasapainoyhtälöä (4a) ja reunaehtoa (5):

$$
a=\int_{A}\left[-\tau_{y x}\left(z-z_{\mathrm{T}}\right)+\tau_{z x}\left(y-y_{\mathrm{T}}\right)\right] \mathrm{d} A+\frac{\partial}{\partial x} \int_{A} \phi \sigma_{x} \mathrm{~d} A .
$$

Sisäinen virtuaalinen työ saa näin muodon

$$
\begin{aligned}
\delta W_{\mathrm{int}}= & -\int_{x_{1}}^{x_{2}}\left[\delta u^{\prime} N-\delta \theta_{z}^{\prime} M_{z}-\delta \theta_{y}^{\prime} M_{y}\right. \\
& \left.+\delta \gamma_{y} Q_{y}+\delta \gamma_{z} Q_{z}+\delta \theta_{x}^{\prime}\left(M_{x}-B^{\prime}\right)-\delta \theta_{x}^{\prime \prime} B\right] \mathrm{d} x
\end{aligned}
$$

missä

$$
\begin{aligned}
& N=\int_{A} \sigma_{x} \mathrm{~d} A, \quad M_{z}=\int_{A} \sigma_{x} y \mathrm{~d} A, \quad M_{y}=\int_{A} \sigma_{z} z \mathrm{~d} A, \quad Q_{y}=\int_{A} \tau_{y x} \mathrm{~d} A, \quad Q_{z}=\int_{A} \tau_{z x} \mathrm{~d} A, \\
& M_{x}=\int_{A}\left[-\tau_{y x}\left(z-z_{\mathrm{T}}\right)+\tau_{z x}\left(y-y_{\mathrm{T}}\right)\right] \mathrm{d} A, \quad B=-\int_{A} \sigma_{x} \phi \mathrm{d} A .
\end{aligned}
$$

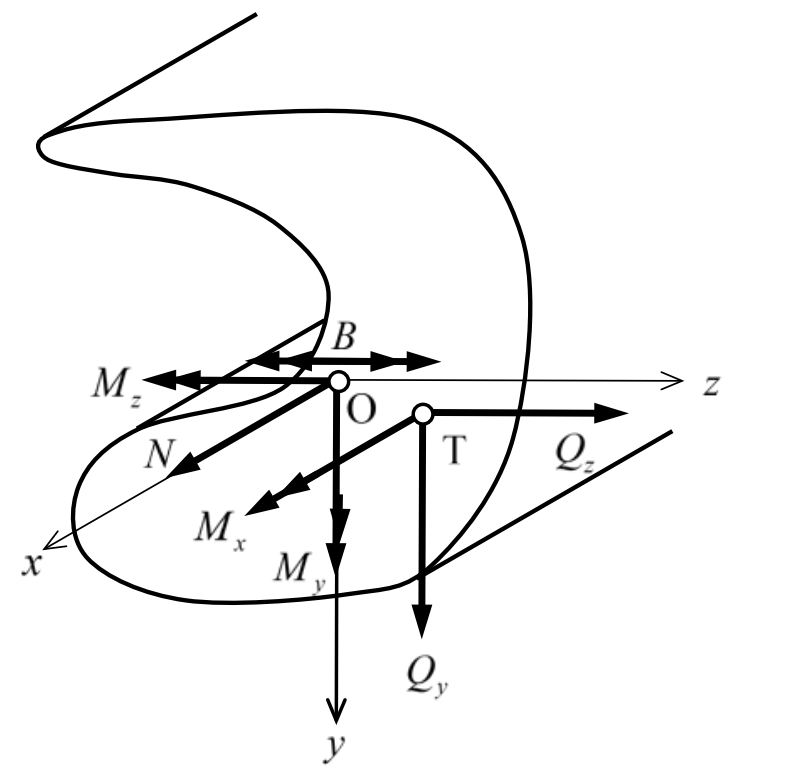

Kuva 1. Poikkileikkauksen jännitysresultantit ja niiden positiiviset suunnat

Lausekkeesta (32) nähdään, että formuloidun tehtävän yleistetyt muodonmuutokset ovat $u^{\prime}$, $-\theta_{z}^{\prime},-\theta_{y}^{\prime}, \gamma_{y}, \gamma_{z}, \theta_{x}^{\prime}$ ja $\theta_{x}^{\prime \prime}$ sekä vastaavat jännitysresultantit ovat samassa järjestyksessä $N$, $M_{z}, M_{y}, Q_{y}, Q_{z}, M_{x}-B^{\prime}$ ja $B$. Sauvan akselin venymä $u^{\prime}$ ja normaalivoima $N$ liittyvät vetoon/puristukseen, käyristymät $-\theta_{z}^{\prime}, \quad-\theta_{y}^{\prime}$ ja taivutusmomenentit $M_{z}, M_{y}$ sekä keskimäääräiset liukumat $\gamma_{y}, \gamma_{z}$ ja leikkausvoimat $Q_{y}, Q_{z}$ taivutukseen sekä vääntökulman 
derivaatat $\theta_{x}^{\prime}, \theta_{x}^{\prime \prime}$ ja jännitysresultantit $M_{x}-B^{\prime}$ ja $B$ vääntöön. Vääntömomentti $M_{x}$ on kaavan (33f) perusteella poikkileikkauksen leikkausjännitysten $\tau_{y x}$ ja $\tau_{z x}$ momentti erityisesti vääntökeskiön T suhteen. Suureelle $B$ käytetään tässä nimitystä käyristymismomentti. Nimitys johtuu siitä, että sekin voidaan kaavan (33g) perusteella ymmärtää eräänlaiseksi normaalijännityksen $\sigma_{x}$ momentiksi, jossa momenttivartena on käyristymisfunktio $\phi$. Kuvassa 1 on esitetty poikkileikkausen jännitysresultantit ja niiden positiiviset suunnat. Nuoli esittää voimaa, kaksoisnuoli momenttia ja kahdesta vastakkaissuuntaisesta kaksoisnuolesta koostuva symboli käyristymismomenttia. Avointen ohutseinämäisten sauvojen vääntöteoriassa (ks. liite F) esiintyy vastaava suure, jota kutsutaan bimomentiksi tai myös käyristymismomentiksi. Sen lauseke (F.12) eroaa lausekkeesta (33g) siinä, että integrandissa on käyristymisfunktion $\phi(y, z)$ sijasta seinämän keskiviivalla $S$ määritelty normeerattu sektoriaalinen koordinaatti $\omega_{\mathrm{T}}(s)$ vääntökeskiön T suhteen (miinusmerkkisenä). Kuvassa 1 käytetty käyristymismomentin symboli ei liene käytössä. Se juontuu kirjallisuudessa esiityvästä symbolista, joka koostuu kahdesta vastakkaissuuntaisesta kaarinuolesta (vrt. [4], s. 189, Kuva 10.4) .

Jännitysresultanttien tasapainoyhtälöiden muodostamista silmälläpitäen muokataan sisäisen virtuaalisen työn lauseketta (32) edelleen. Ottamalla huomioon yhteydet $\delta \gamma_{y}=\delta v^{\prime}-\delta \theta_{z}$ ja $\delta \gamma_{z}=\delta w^{\prime}-\delta \theta_{y}$ saadaan

$$
\begin{aligned}
\delta W_{\text {int }}=\int_{x_{1}}^{x_{2}}\left[-\delta u^{\prime} N+\delta \theta_{z}^{\prime} M_{z}+\delta \theta_{y}^{\prime} M_{y}-\delta v^{\prime} Q_{y}-\delta w^{\prime} Q_{z}\right. \\
\left.+\delta \theta_{z} Q_{y}+\delta \theta_{y} Q_{z}-\delta \theta_{x}^{\prime}\left(M_{x}-B^{\prime}\right)+\delta \theta_{x}^{\prime \prime} B\right] \mathrm{d} x
\end{aligned}
$$

Suorittamalla ensin osittaisintegrointi integrandin viimeiseen termiin liittyen saadaan

$$
\begin{gathered}
\delta W_{\text {int }}=\int_{x_{1}}^{x_{2}}\left(-\delta u^{\prime} N+\delta \theta_{z}^{\prime} M_{z}+\delta \theta_{y}^{\prime} M_{y}-\delta v^{\prime} Q_{y}-\delta w^{\prime} Q_{z}\right. \\
\left.+\delta \theta_{z} Q_{y}+\delta \theta_{y} Q_{z}-\delta \theta_{x}^{\prime} M_{x}\right) \mathrm{d} x+\left.\right|_{x_{1}} ^{x_{2}} \delta \theta_{x}^{\prime} B .
\end{gathered}
$$

Suorittamalla lisää osittaisintegrointeja saadaan

$$
\begin{aligned}
\delta W_{\mathrm{int}}= & \int_{x_{1}}^{x_{2}}\left(\delta u N^{\prime}-\delta \theta_{z} M_{z}^{\prime}-\delta \theta_{y} M_{y}^{\prime}+\delta v Q_{y}^{\prime}+\delta w Q_{z}^{\prime}+\delta \theta_{z} Q_{y}+\delta \theta_{y} Q_{z}+\delta \theta_{x} M_{x}^{\prime}\right) \mathrm{d} x \\
& +\left.\right|_{x_{1}} ^{x_{2}}\left(-\delta u N+\delta \theta_{z} M_{z}+\delta \theta_{y} M_{y}-\delta v Q_{y}-\delta w Q_{z}-\delta \theta_{x} M_{x}+\delta \theta_{x}^{\prime} B\right) \\
= & \int_{x_{1}}^{x_{2}}\left(\delta u N^{\prime}-\delta \theta_{z} M_{z}^{\prime}-\delta \theta_{y} M_{y}^{\prime}+\delta v Q_{y}^{\prime}+\delta w Q_{z}^{\prime}+\delta \theta_{z} Q_{y}+\delta \theta_{y} Q_{z}+\delta \theta_{x} M_{x}^{\prime}\right) \mathrm{d} x \\
& +\delta u\left(x_{1}\right) N\left(x_{1}\right)-\delta u\left(x_{2}\right) N\left(x_{2}\right) \\
& -\delta \theta_{z}\left(x_{1}\right) M_{z}\left(x_{1}\right)+\delta \theta_{z}\left(x_{2}\right) M_{z}\left(x_{2}\right)-\delta \theta_{y}\left(x_{1}\right) M_{y}\left(x_{1}\right)+\delta \theta_{y}\left(x_{2}\right) M_{y}\left(x_{2}\right) \\
& +\delta v\left(x_{1}\right) Q_{y}\left(x_{1}\right)-\delta v\left(x_{2}\right) Q_{y}\left(x_{2}\right)+\delta w\left(x_{1}\right) Q_{z}\left(x_{1}\right)-\delta w\left(x_{2}\right) Q_{z}\left(x_{2}\right) \\
& +\delta \theta_{x}\left(x_{1}\right) M_{x}\left(x_{1}\right)-\delta \theta_{x}\left(x_{2}\right) M_{x}\left(x_{2}\right) \\
& -\delta \theta_{x}^{\prime}\left(x_{1}\right) B\left(x_{1}\right)+\delta \theta_{x}^{\prime}\left(x_{2}\right) B\left(x_{2}\right) .
\end{aligned}
$$

Palkin ulkoiselle virtualiselle työlle voidaan kirjoittaa lauseke 


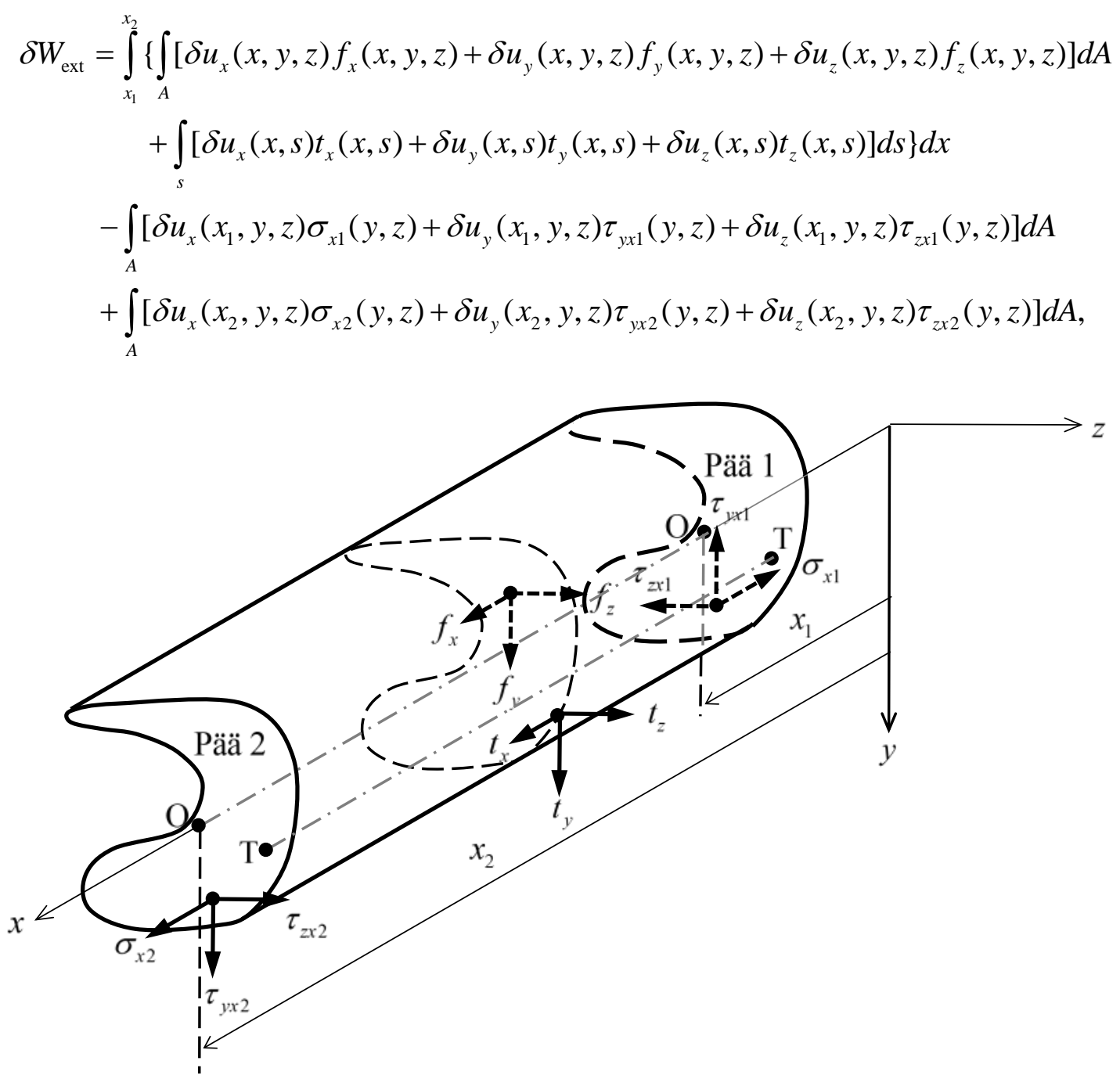

Kuva 2. Palkin osaan kohdistuvat pinta- ja tilavuusvoimat.

missä $f_{x}, f_{y}$ ja $f_{z}$ ovat tilavuusvoiman komponentit, $t_{x}, t_{y}$ ja $t_{z}$ palkin sylinterimäiseen pitkittäisreunaan kohdistuva kuormitus ilmaistuna traktiokomponentteina sekä $\sigma_{x i}, \tau_{y x i}, \tau_{z x i}$, $i=1$, 2 sen päätypoikkileikkauksiin 1 ja 2 kohdistuva kuormitus ilmaistuna jännityskomponentteina. (Vaikka pitkittäisreuna otaksuttiin reunaehtoyhtälön (5) yhteydessä kuormittamattomaksi, tässä tarkastelussa, jonka tuloksena selviää muun muassa kuinka palkin pituutta kohti vaikuttava jakautunut kuormitus muotoutuu, tätä oletusta ei ole tarpeen tehdä.) Kaavoja (25) soveltaen saadaan 


$$
\begin{aligned}
\delta W_{\mathrm{ext}} & =\int_{x_{1}}^{x_{2}}\left\{\delta u(x)\left[\int_{A} f_{x}(x, y, z) \mathrm{d} A+\int_{s} t_{x}(x, s) \mathrm{d} s\right]\right. \\
& -\delta \theta_{z}(x)\left[\int_{A} f_{x}(x, y, z) y \mathrm{~d} A+\int_{A} t_{x}(x, s) y(s) \mathrm{d} s\right] \\
& -\delta \theta_{y}(x)\left[\int_{A} f_{x}(x, y, z) z \mathrm{~d} A+\int_{A} t_{x}(x, s) z(s) \mathrm{d} s\right] \\
& +\delta \theta_{x}^{\prime}(x)\left[\int_{A} f_{x}(x, y, z) \phi(y, z) \mathrm{d} A+\int_{A} t_{x}(x, s) \phi(y(s), z(s)) \mathrm{d} s\right] \\
& +\delta v(x)\left[\int_{A} f_{y}(x, y, z) \mathrm{d} A+\int_{s} t_{y}(x, s) \mathrm{d} s\right]+\delta w(x)\left[\int_{A} f_{z}(x, y, z) \mathrm{d} A+\int_{s} t_{z}(x, s) \mathrm{d} s\right] \\
& +\delta \theta_{x}(x)\left\{\int_{A}\left[-f_{y}(x, y, z)\left(z-z_{\mathrm{T}}\right)+f_{z}(x, y, z)\left(y-y_{\mathrm{T}}\right)\right] \mathrm{d} A\right. \\
& \left.\left.-\delta u\left(x_{1}\right) \int_{A}\left[-t_{y}(x, s)\left(z(s)-z_{\mathrm{T}}\right)+t_{z}(x, s)\left(y(s)-y_{\mathrm{T}}\right)\right] \mathrm{d} s\right\}\right\} \mathrm{d} x \\
+ & \delta \theta_{z}\left(x_{1}\right) \int_{A} \sigma_{x 1} y \mathrm{~d} A-\delta \theta_{z}\left(x_{2}\right) \int_{A} \sigma_{x 2} y \mathrm{~d} A+\delta \theta_{y}\left(x_{1}\right) \int_{A} \sigma_{x 1} z \mathrm{~d} A-\delta \theta_{y}\left(x_{2}\right) \int_{A} \sigma_{x 2} z \mathrm{~d} A \\
& \delta \theta_{x}^{\prime}\left(x_{1}\right) \int_{A} \sigma_{x 1} \phi \mathrm{d} A+\delta \theta_{x}^{\prime}\left(x_{2}\right) \int_{A} \sigma_{x 2} \phi \mathrm{d} A \\
& \delta v\left(x_{1}\right) \int_{A} \tau_{y x 1} \mathrm{~d} A+\delta v\left(x_{2}\right) \int_{A} \tau_{y x 2} \mathrm{~d} A-\delta w\left(x_{1}\right) \int_{A} \tau_{z x 1} \mathrm{~d} A+\delta w\left(x_{2}\right) \int_{A} \tau_{z x 2} \mathrm{~d} A \\
- & \delta \theta_{x}\left(x_{1}\right) \int_{A}\left[-\tau_{y x 1}\left(z-z_{\mathrm{T}}\right)+\tau_{z x 1}\left(y-y_{\mathrm{T}}\right)\right] \mathrm{d} A \\
+ & \delta \theta_{x}\left(x_{2}\right) \int_{A}\left[-\tau_{y x 2}\left(z-z_{\mathrm{T}}\right)+\tau_{z x 2}\left(y-y_{\mathrm{T}}\right)\right] \mathrm{d} A \\
&
\end{aligned}
$$

eli

$$
\begin{aligned}
\delta W_{\mathrm{ext}}= & \int_{x_{1}}^{x_{2}}\left[\delta u(x) q_{x}(x)-\delta \theta_{z}(x) m_{z}(x)-\delta \theta_{y}(x) m_{y}(x)-\delta \theta_{x}^{\prime}(x) b(x)\right. \\
& \left.+\delta v(x) q_{y}(x)+\delta w(x) q_{z}(x)+\delta \theta_{x}(x) m_{x}(x)\right] \mathrm{d} x \\
& -\delta u\left(x_{1}\right) N_{1}+\delta u\left(x_{2}\right) N_{2} \\
& +\delta \theta_{z}\left(x_{1}\right) M_{z 1}-\delta \theta_{z}\left(x_{2}\right) M_{z 2} \\
& +\delta \theta_{y}\left(x_{1}\right) M_{y 1}-\delta \theta_{y}\left(x_{2}\right) M_{y 2} \\
& +\delta \theta_{x}^{\prime}\left(x_{1}\right) B_{1}-\delta \theta_{x}^{\prime}\left(x_{2}\right) B_{2} \\
& -\delta v\left(x_{1}\right) Q_{y 1}+\delta v\left(x_{2}\right) Q_{y 2} \\
& -\delta w\left(x_{1}\right) Q_{z 1}+\delta w\left(x_{2}\right) Q_{z 2} \\
& -\delta \theta_{x}\left(x_{1}\right) M_{x 1}+\delta \theta_{x}\left(x_{2}\right) M_{x 2}
\end{aligned}
$$

missä 


$$
\begin{aligned}
& q_{x}=\int_{A} f_{x} \mathrm{~d} A+\int_{s} t_{x} \mathrm{~d} s, \quad q_{y}=\int_{A} f_{y} \mathrm{~d} A+\int_{s} t_{y} \mathrm{~d} s, \quad q_{z}=\int_{A} f_{z} \mathrm{~d} A+\int_{s} t_{z} \mathrm{~d} s, \\
& m_{x}=\int_{A}\left[-f_{y}\left(z-z_{\mathrm{T}}\right)+f_{z}\left(y-y_{\mathrm{T}}\right)\right] \mathrm{d} A+\int_{s}\left[-t_{y}\left(z-z_{\mathrm{T}}\right)+t_{z}\left(y-y_{\mathrm{T}}\right)\right] \mathrm{d} s, \\
& m_{y}=\int_{A} f_{x} z \mathrm{~d} A+\int_{s} t_{x} z \mathrm{~d} s, \quad m_{z}=\int_{A} f_{x} y \mathrm{~d} A+\int_{s} t_{x} y \mathrm{~d} s, \quad b=-\int_{A} f_{x} \phi \mathrm{d} A-\int_{s} t_{x} \phi \mathrm{d} s, \\
& N_{i}=\int_{A} \sigma_{x i} \mathrm{~d} A, \quad M_{z i}=\int_{A} \sigma_{x i} y \mathrm{~d} A, \quad M_{y i}=\int_{A} \sigma_{x i} z \mathrm{~d} A, \quad B_{i}=-\int_{A} \sigma_{x i} \phi \mathrm{d} A, \\
& Q_{y i}=\int_{A} \tau_{y x i} \mathrm{~d} A, \quad Q_{z i}=\int_{A} \tau_{z x i} \mathrm{~d} A, \quad M_{x i}=\int_{A}\left[-\tau_{y x i}\left(z-z_{\mathrm{T}}\right)+\tau_{z x i}\left(y-y_{\mathrm{T}}\right)\right] \mathrm{d} A .
\end{aligned}
$$

Suureet $q_{x}(x) q_{y}(x), q_{z}(x), m_{x}(x), m_{y}(x)$ ja $m_{z}(x)$ ovat palkin pituutta kohti jakautuneen kuormituksen ja vääntökeskiöakselin suhteen lasketun jakautuneen momenttikuormituksen komponentit. Suuretta $b(x)$ kutsutaan tässä jakautuneeksi käyristymismomenttikuormitukseksi. Suureet $N_{i}, M_{x i}, M_{y i}, M_{z i}, Q_{y i}, Q_{z i}, B_{i} i=1,2$ ovat normaalivoiman, vääntömomentin, taivutusmomenttien, leikkausvoimien ja käyristymismomentin arvot palkin päissä 1 ja 2.

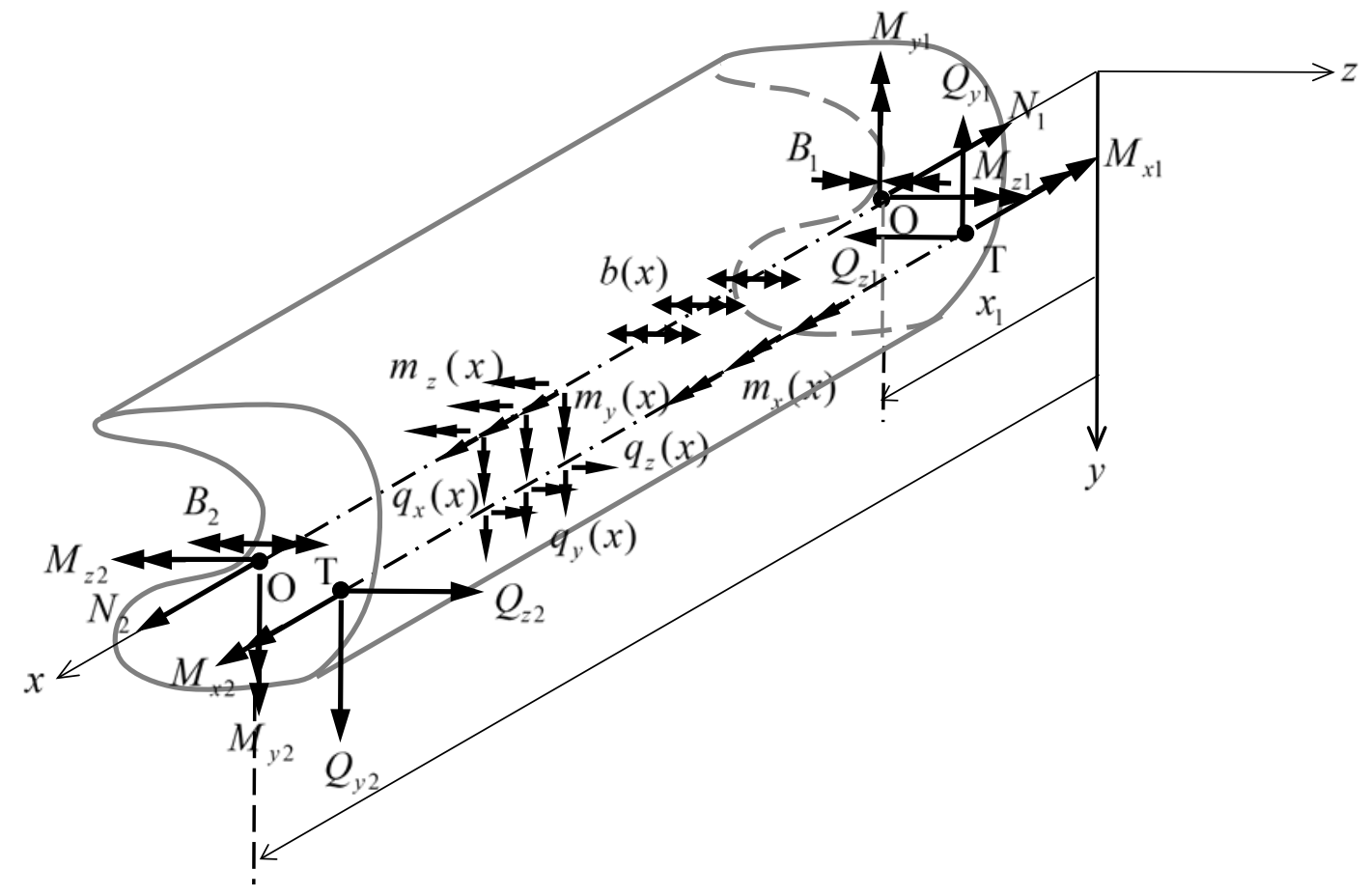

Kuva 3. Palkin osaan kohdistuvat yleistetyt voimat.

Suoritetaan vielä lausekkeen (39) integraalin integrandin neljänteen termiin liittyvä osittaisintegrointi, jolloin saadaan 


$$
\begin{aligned}
\delta W_{\mathrm{ext}}= & \int_{x_{1}}^{x_{2}}\left\{\delta u(x) q_{x}(x)-\delta \theta_{z}(x) m_{z}(x)-\delta \theta_{y}(x) m_{y}(x)\right. \\
& \left.+\delta v(x) q_{y}(x)+\delta w(x) q_{z}(x)+\delta \theta_{x}(x)\left[m_{x}(x)+b^{\prime}(x)\right]\right\} \mathrm{d} x \\
& -\delta u\left(x_{1}\right) N_{1}+\delta u\left(x_{2}\right) N_{2} \\
& +\delta \theta_{z}\left(x_{1}\right) M_{z 1}-\delta \theta_{z}\left(x_{2}\right) M_{z 2}+\delta \theta_{y}\left(x_{1}\right) M_{y 1}-\delta \theta_{y}\left(x_{2}\right) M_{y 2} \\
& +\delta \theta_{x}^{\prime}\left(x_{1}\right) B_{1}-\delta \theta_{x}^{\prime}\left(x_{2}\right) B_{2} \\
& -\delta v\left(x_{1}\right) Q_{y 1}+\delta v\left(x_{2}\right) Q_{y 2}-\delta w\left(x_{1}\right) Q_{z 1}+\delta w\left(x_{2}\right) Q_{z 2} \\
& -\delta \theta_{x}\left(x_{1}\right)\left[M_{x 1}-b\left(x_{1}\right)\right]+\delta \theta_{x}\left(x_{2}\right)\left[M_{x 2}-b\left(x_{2}\right)\right] .
\end{aligned}
$$

Virtuaalisen työn periaate

$$
\delta W_{\text {int }}+\delta W_{\text {ext }}=0
$$

antaa yhtälön

$$
\begin{aligned}
& \int_{x_{1}}^{x_{2}}\left[\delta u\left(N^{\prime}+q_{x}\right)-\delta \theta_{z}\left(M_{z}^{\prime}-Q_{y}+m_{z}\right)-\delta \theta_{y}\left(M_{y}^{\prime}-Q_{z}+m_{y}\right)\right. \\
& \left.+\delta v\left(Q_{y}^{\prime}+q_{y}\right)+\delta w\left(Q_{z}^{\prime}+q_{z}\right)+\delta \theta_{x}\left(M_{x}^{\prime}+m_{x}+b^{\prime}\right)\right] \mathrm{d} x \\
& \quad+\delta u\left(x_{1}\right)\left[N\left(x_{1}\right)-N_{1}\right]-\delta u\left(x_{2}\right)\left[N\left(x_{2}\right)-N_{2}\right] \\
& \quad-\delta \theta_{z}\left(x_{1}\right)\left[M_{z}\left(x_{1}\right)-M_{z 1}\right]+\delta \theta_{z}\left(x_{2}\right)\left[M_{z}\left(x_{2}\right)-M_{z 2}\right] \\
& \quad-\delta \theta_{y}\left(x_{1}\right)\left[M_{y}\left(x_{1}\right)-M_{y 1}\right]+\delta \theta_{y}\left(x_{2}\right)\left[M_{y}\left(x_{2}\right)-M_{y 2}\right] \\
& \quad+\delta v\left(x_{1}\right)\left[Q_{y}\left(x_{1}\right)-Q_{y 1}\right]-\delta v\left(x_{2}\right)\left[Q_{y}\left(x_{2}\right)-Q_{y 2}\right] \\
& \quad+\delta w\left(x_{1}\right)\left[Q_{z}\left(x_{1}\right)-Q_{z 1}\right]-\delta w\left(x_{2}\right)\left[Q_{z}\left(x_{2}\right)-Q_{z 2}\right] \\
& \quad+\delta \theta_{x}\left(x_{1}\right)\left[M_{x}\left(x_{1}\right)-M_{x 1}+b\left(x_{1}\right)\right]-\delta \theta_{x}\left(x_{2}\right)\left[M_{x}\left(x_{2}\right)-M_{x 2}+b\left(x_{2}\right)\right] \\
& \quad-\delta \theta_{x}^{\prime}\left(x_{1}\right)\left[B\left(x_{1}\right)-B_{1}\right]+\delta \theta_{x}^{\prime}\left(x_{2}\right)\left[B\left(x_{2}\right)-B_{2}\right]=0 .
\end{aligned}
$$

Virtuaalisen työn periaatteen yhteydessä tunnettuun tapaan voidaan yhtälön (43) perusteella johtaa seuraavat yhtälöt: Jännitysresultanttien differentiaaliset tasapainoyhtälöt

$$
\begin{aligned}
& N^{\prime}+q_{x}=0, \\
& M_{z}^{\prime}-Q_{y}+m_{z}=0, \quad M_{y}^{\prime}-Q_{z}+m_{y}=0, \quad Q_{y}^{\prime}+q_{y}=0, \quad Q_{z}^{\prime}+q_{z}=0, \\
& M_{x}^{\prime}+m_{x}+b^{\prime}=0,
\end{aligned}
$$

jotka ovat voimassa palkin alueella $x_{1}<x<x_{2}$. Kinemaattiset reunaehdot

$$
\begin{aligned}
& u\left(x_{i}\right)=u_{i} \text {, } \\
& \theta_{z}\left(x_{i}\right)=\theta_{z i}, \quad \theta_{y}\left(x_{i}\right)=\theta_{y i}, \quad v\left(x_{i}\right)=v_{i}, \quad w\left(x_{i}\right)=w_{i}, \\
& \theta_{x}\left(x_{i}\right)=\theta_{x i}, \quad \theta_{x}^{\prime}\left(x_{i}\right)=\theta_{x i}^{\prime}
\end{aligned}
$$

ja niitä vastaavat kineettiset reunaehdot

$$
\begin{aligned}
& N\left(x_{i}\right)=N_{i}, \\
& M_{z}\left(x_{i}\right)=M_{z i}, \quad M_{y}\left(x_{i}\right)=M_{y i}, \quad Q_{y}\left(x_{i}\right)=Q_{y i}, \quad Q_{z}\left(x_{i}\right)=Q_{z i}, \\
& M_{x}\left(x_{i}\right)=M_{x i}-b\left(x_{i}\right), \quad B\left(x_{i}\right)=B_{i},
\end{aligned}
$$

jotka ovat voimassa palkin päissä $i=1$ ja 2 . Kustakin toisiaan vastaavasta kinemaattisesta ja kineettisestä reunaehdosta tulee olla voimassa jompi kumpi.

Virtuaalisen työn periaatetta käyttäen saatiin siis muodostettua palkin jännitysresultit (33), kuormituksen määrittely (40), jännitysresultanttien differentiaaliset tasapainoyhtälöt (44) sekä 
kinemaattiset ja kineettiset reunaehtotyypit (45) ja (46). Kaavojen (44), (45) ja (46) ylimmäiset yhtälöt liittyvät vetoon/puristutukseen, keskimmäiset taivutukseen ja alimmaiset vääntöön. Jos sovelletaan jäykän kappaleen tasapainoehtoja differentiaaliseen sauva-alkioon, saadaan tulokseksi differentiaaliset tasapainoyhtälöt, jotka poikkeavat yhtälöistä (44) siinä, että viimeisestä (44f) puuttuu termi $b^{\prime}$. Ilman energiatarkastelua jää myös reunaehtoyhtälöstä (46f) termi $b\left(x_{i}\right)$ pois. Näin menetellen jää käyristymismomenttikuormitus $b(x)$ käsitteenä ja sen vaikutus yhtälöihin (44) ja (46) tarkastelusta pois. Käyristymismomenttikuormitus $b(x)$ on kuitenkin vaikutukseltaan vähäinen.

\section{Jännitysresultanttien ja yleistettyjen muodonmuutosten yhteydet}

Tavoitteena on nyt lausua tehtävän jännitysresultantit niitä vastaavien yleistettyjen muodonmuutosten avulla. Kysymyksessä on tiettyyn poikkileikkaukseen liittyvä paikallinen tarkastelu, jonka yhteydessä voidaan soveltaa kohdan 1.3 mukaisia paikallisia otaksumia.

\subsection{Normaalivoima, taivutusmomentit ja käyristymismomentti}

Käyttäen normaalivoiman, taivutusmomenttien ja käyristymismomentin määrittelykaavoja (33a), (33b), (33c) ja (33g) sekä normaalijännityksen lauseketta (18a) saadaan

$$
\begin{aligned}
& N=E A u^{\prime}-E S_{y} \theta_{y}^{\prime}-E S_{z} \theta_{z}^{\prime}+E S_{\phi} \theta_{x}^{\prime \prime}, \\
& M_{y}=E S_{y} u^{\prime}-E I_{y} \theta_{y}^{\prime}-E I_{y z} \theta_{z}^{\prime}+E I_{y \phi} \theta_{x}^{\prime \prime}, \\
& M_{z}=E S_{z} u^{\prime}-E I_{y z} \theta_{y}^{\prime}-E I_{z} \theta_{z}^{\prime}+E I_{z \phi} \theta_{x}^{\prime \prime}, \\
& B=-E S_{\phi} u^{\prime}+E I_{y \phi} \theta_{y}^{\prime}+E I_{z \phi} \theta_{z}^{\prime}-E I_{\phi} \theta_{x}^{\prime \prime},
\end{aligned}
$$

missä

$$
\begin{aligned}
& E A=\int_{A} E \mathrm{~d} A, E S_{y}=\int_{A} E z \mathrm{~d} A, E S_{z}=\int_{A} E y \mathrm{~d} A, E S_{\phi}=\int_{A} E \phi \mathrm{d} A, \\
& E I_{y}=\int_{A} E z^{2} \mathrm{~d} A, E I_{z}=\int_{A} E y^{2} \mathrm{~d} A, E I_{y z}=\int_{A} E y z \mathrm{~d} A, \\
& E I_{y \phi}=\int_{A} E z \phi \mathrm{d} A, E I_{z \phi}=\int_{A} E y \phi \mathrm{d} A, E I_{\phi}=\int_{A} E \phi^{2} \mathrm{~d} A .
\end{aligned}
$$

Jännitysresultanttien ja yleistettyjen muodonmuutosten yhteyksien (47) kertoimille käytetään tässä kaksikirjaimisia symboleja, kuten sauvateorian esityksissä usein menetellään. Jos poikkileikkaus on homogeeninen ja kimmomoduuli $E$ vakio, se voidaan ottaa integraalin ulkopuolelle. Tällöin kirjainyhdistelmä ymmärretään kimmomoduulin $E$ ja sitä seuraavan integraalin (poikkileikkauksen geometrisen suureen) tuloksi. Esimerkiksi aksiaalijäykkyys $E A$ on kimmomoduulin $E$ ja poikkipinnan alan $A$ tulo, kimmomoduulilla painotettu staattinen momentti $E S_{z}$ kimmomoduulin $E$ ja staattisen momentin $S_{z}$ tulo ja taivutusjäykkyys $E I_{z}$ on kimmomoduulin $E$ ja jäyhyysmomentin $I_{z}$ tulo. Suureelle $E I_{\phi}$ käytetään nimistystä käyristymisjäykkyys ja homogeenisen poikkileikkauksen suureelle $I_{\phi}$ käyristymisjäyhyysmomentti. Avointen ohutseinämäisten sauvojen vääntöteoriassa yhteydet (47) ovat samanmuotoiset. Suureita $E S_{\phi}, E I_{y \phi}, E I_{z \phi}$ ja $E I_{\phi}$ vastaa, kun kysymyksessä on homogeeninen poikkileikkaus, tulot $E S_{\omega}, E I_{y \omega}, E I_{z \omega}$ ja $E I_{\omega}$, missä $S_{\omega}$ on sektoriaalinen staattinen momentti, $I_{y \omega}$ ja $I_{z \omega}$ ovat sektoriaaliset tulomomentit sekä $I_{\omega}$ on sektoriaalinen jäyhyysmomentti (vrt. liitteen F kaavat (F.4)), jotka on määritetty käyttäen poikkileikauksen normeerattua sektoriaalista koordinaattia $\omega_{\mathrm{T}}$ vääntökeskiön suhteen. 
Menetellään ensin kuten tavallisesti sauvateoriassa. Asetetaan $y, z$-koordinaatiston origo O poikkileikkauksen vetojäykkyyskeskiöön, jolloin

$$
E S_{y}=0, \quad E S_{z}=0 .
$$

Koordinaattiakselien suunnat voitaisiin myös asettaa yhtymään poikkileikkauksen pääjäykkyyksien suuntiin, jolloin

$$
E I_{y z}=0 \text {. }
$$

Näin ei kuitenkaan tässä yhteydessä tehdä, koska siitä ei ole sanottavaa hyötyä. Määritetään sitten yhtälön (16a) vakio $\Delta_{\Phi}$ ja vääntökeskiön T koordinaatit $y_{\mathrm{T}}$ ja $z_{\mathrm{T}}$ siten, että jäykkyydet $E S_{\phi}, E I_{y \phi}$ ja $E I_{z \phi}$ häviävät. Kaavojen (48), (16a) ja (49) perusteella saadaan yhtälöt

$$
\begin{aligned}
& E S_{\phi} \equiv \int_{A} E \phi \mathrm{d} A=E S_{\Phi}+\Delta_{\Phi} E A=0, \\
& E I_{y \phi} \equiv \int_{A} E z \phi \mathrm{d} A=E I_{y \Phi}-z_{\mathrm{T}} E I_{y z}+y_{\mathrm{T}} E I_{y}=0, \\
& E I_{z \phi} \equiv \int_{A} E y \phi \mathrm{d} A=E I_{z \Phi}-z_{\mathrm{T}} E I_{z}+y_{\mathrm{T}} E I_{y z}=0 .
\end{aligned}
$$

missä

$$
E S_{\Phi}=\int_{A} E \Phi \mathrm{d} A, \quad E I_{y \Phi}=\int_{A} E z \Phi \mathrm{d} A, \quad E I_{z \Phi}=\int_{A} E y \Phi \mathrm{d} A .
$$

Yhtälöiden (51) ratkaisu on

$$
\Delta_{\Phi}=-\frac{E S_{\Phi}}{E A}, \quad\left\{\begin{array}{l}
y_{\mathrm{T}} \\
z_{\mathrm{T}}
\end{array}\right\}=\frac{1}{E I_{y} E I_{z}-E I_{y z}^{2}}\left[\begin{array}{cc}
E I_{z} & E I_{y z} \\
E I_{y z} & E I_{y}
\end{array}\right]\left\{\begin{array}{c}
-E I_{y \Phi} \\
E I_{z \Phi}
\end{array}\right\} .
$$

Kun käyristymisfunktio $\Phi(y, z)$, jonka nollapiste on $\mathrm{P}_{0}$, on määritetty reuna-arvotehtävän (21a) ratkaisuna, voidaan vakio $\Delta_{\Phi}$ ja vääntökeskiön koordinaatit $y_{\mathrm{T}}$ ja $z_{\mathrm{T}}$ määrittää kaavoilla (53). Tämän jälkeen käyristymisfunktio $\phi(y, z)$ voidaan määrittää kaavaa (16a) käyttäen. Kun se tunnetaan, voidaan määrittää käyristymisjäykkyys $E I_{\phi}$. Avointen ohutseinämäisten sauvojen teoriassa esiintyy analoginen prosessi, jota on kuvattu liitteessä F. Siinä käyristymisfuntiota $\Phi(y, z)$ vastaa sektoriaalinen koordinaatti $\Omega_{\mathrm{O}}(s)$ origon suhteen, jonka nollapiste on $\mathrm{P}_{0}$, kaavoja (53) vastaa kaavat (F.11) ja (F.10), Käyristymisfunktiota $\phi(y, z)$ vastaa normeerattu sektoriaalinen koordinaatti $\omega_{\mathrm{T}}(s)$ vääntökeskiön $\mathrm{T}$ suhteen, joka määritetään kaavaa (16a) vastaavalla kaavalla (F.9). Normeerattua sektoriaalista koordinaattia $\omega_{\mathrm{T}}(s)$ käyttäen voidaan sitten määrittää sektoriaalinen jäyhyysmomentti $I_{\omega}$ kaavalla (F4d).

Jännitysresultanttien ja yleistettyjen muodonmuutosten yhteydet (47) yksinkertaistuvat nyt seuraaviksi

$$
\begin{aligned}
& N=E A u^{\prime}, \\
& \left\{\begin{array}{l}
M_{z} \\
M_{y}
\end{array}\right\}=-\left[\begin{array}{cc}
E I_{z} & E I_{y z} \\
E I_{y z} & E I_{y}
\end{array}\right]\left\{\begin{array}{l}
\theta_{z}^{\prime} \\
\theta_{y}^{\prime}
\end{array}\right\}, \\
& B=-E I_{\phi} \theta_{x}^{\prime \prime} .
\end{aligned}
$$

Näissä lausekkeissa normaalivoima riippuu vain akselin venymästä, taivutusmomentit riippuvat vain käyristymistä ja käyristymismomentti vain vääntökulman toisesta derivaatasta. Näin kytkennät, jotka lausekkeissa (47) olivat veto/puristus-, taivutus- ja vääntötehtävän välillä, on saatu hävitettyä. 


\subsection{Leikkausvoimat}

Käyttäen leikkausvoimien määrittelykaavoja (33d) ja (33e) sekä leikkausjännitysten lausekkeita (18b) ja (18c) saadaan

$$
\begin{aligned}
Q_{y} & =-\theta_{z}^{\prime \prime} \int_{A} G \frac{\partial \Psi_{y}}{\partial y} \mathrm{~d} A-\theta_{y}^{\prime \prime} \int_{A} G \frac{\partial \Psi_{z}}{\partial y} \mathrm{~d} A+\theta_{x}^{\prime} \int_{A} G\left(\frac{\partial \Phi}{\partial y}-z\right) \mathrm{d} A+\theta_{x}^{\prime \prime \prime} \int_{A} G \frac{\partial \Psi_{x}}{\partial y} \mathrm{~d} A \\
& =-\theta_{z}^{\prime \prime} \int_{A} E y^{2} \mathrm{~d} A-\theta_{y}^{\prime \prime} \int_{A} E y z \mathrm{~d} A+\theta_{x}^{\prime \prime \prime} \int_{A} E y \phi \mathrm{d} A=-E I_{z} \theta_{z}^{\prime \prime}-E I_{y z} \theta_{y}^{\prime \prime}+E I_{z \phi} \theta_{x}^{\prime \prime \prime} \\
& =-E I_{z} \theta_{z}^{\prime \prime}-E I_{y z} \theta_{y}^{\prime \prime}, \\
Q_{z} & =-\theta_{z}^{\prime \prime} \int_{A} G \frac{\partial \Psi_{y}}{\partial z} \mathrm{~d} A-\theta_{y}^{\prime \prime} \int_{A} G \frac{\partial \Psi_{z}}{\partial z} \mathrm{~d} A+\theta_{x}^{\prime} \int_{A} G\left(\frac{\partial \Phi}{\partial z}+y\right) \mathrm{d} A+\theta_{x}^{\prime \prime \prime} \int_{A} G \frac{\partial \Psi_{x}}{\partial z} \mathrm{~d} A \\
& =-\theta_{z}^{\prime \prime} \int_{A} E y z \mathrm{~d} A-\theta_{y}^{\prime \prime} \int_{A} E z^{2} \mathrm{~d} A+\theta_{x}^{\prime \prime \prime} \int_{A} E z \phi \mathrm{d} A=-E I_{y z} \theta_{z}^{\prime \prime}-E I_{y} \theta_{y}^{\prime \prime}+E I_{y \phi} \theta_{x}^{\prime \prime \prime} \\
& =-E I_{y z} \theta_{z}^{\prime \prime}-E I_{y} \theta_{y}^{\prime \prime} .
\end{aligned}
$$

Sovellettiin heikon muodon yhtälöitä (22), joissa ensin $\hat{\Phi}=y, \hat{\Psi}_{x}=y, \hat{\Psi}_{y}=y, \hat{\Psi}_{z}=y$ ja sitten $\hat{\Phi}=z, \hat{\Psi}_{x}=z, \hat{\Psi}_{y}=z, \hat{\Psi}_{z}=z$, sekä otettiin lopuksi huomioon yhteydet (51b) ja (51c). Derivoimalla taivutusmomenttien lausekkeet (54b) nähdään, että yhtälöistä (55) seuraa leikkausvoimille tulokset

$$
Q_{y}=M_{z}^{\prime}, \quad Q_{z}=M_{y}^{\prime} .
$$

Nämä lausekkeet ovat tasapainoyhtälöiden (44b) ja (44c) paikallisesti voimassa olevat versiot, joissa $m_{y}=0$ ja $m_{z}=0$. Koska leikkausvoimien lausekkeet (55) sisältävät saman informaation kuin jännitysresultanttien tasapainoyhtälöt, ei niitä voida käyttää jännitysresultanttien ja yleistettyjen muodonmuutosten yhteyksinä.

Leikkausvoimien lausekkeet (55) muodostettiin integroimalla leikkausjännitysten lausekkeet (18b) ja (18c), jotka perustuivat siirtymäapproksimaation (9) lisäsiirtymän lausekkeeseen (10). Menetellään nyt niin, että lisäsiirtymäksi ei oteta koko lauseketta (10), vaan sen kaksi ensimmäistä termiä. Leikkausjännityksiksi tässä tapauksessa saadaan

$$
\begin{aligned}
& \tau_{y x}=G\left[\gamma_{y}+\theta_{x}^{\prime}\left(\frac{\partial \Phi}{\partial y}-z\right)+\theta_{x}^{\prime \prime \prime} \frac{\partial \Psi_{x}}{\partial y}\right], \\
& \tau_{z x}=G\left[\gamma_{z}+\theta_{x}^{\prime}\left(\frac{\partial \Phi}{\partial z}+y\right)+\theta_{x}^{\prime \prime \prime} \frac{\partial \Psi_{x}}{\partial z}\right] .
\end{aligned}
$$

Käyttäen leikkausvoimien määrittelykaavoja (33d) ja (33e) sekä leikkausjännitysten lausekkeita (57) saadaa

$$
\begin{aligned}
Q_{y} & =\gamma_{y} \int_{A} G \mathrm{~d} A+\theta_{x}^{\prime} \int_{A} G\left(\frac{\partial \Phi}{\partial y}-z\right) \mathrm{d} A+\theta_{x}^{\prime \prime \prime} \int_{A} G \frac{\partial \Psi_{x}}{\partial y} \mathrm{~d} A=\gamma_{y} \int_{A} G \mathrm{~d} A+\theta_{x}^{\prime \prime \prime} \int_{A} E y \phi \mathrm{d} A \\
& =G A \gamma_{y}+E I_{z \phi} \theta_{x}^{\prime \prime \prime}=G A \gamma_{y}, \\
Q_{z} & =\gamma_{z} \int_{A} G \mathrm{~d} A+\theta_{x}^{\prime} \int_{A} G\left(\frac{\partial \Phi}{\partial z}+y\right) \mathrm{d} A+\theta_{x}^{\prime \prime \prime} \int_{A} G \frac{\partial \Psi_{x}}{\partial z} \mathrm{~d} A=\gamma_{z} \int_{A} G \mathrm{~d} A+\theta_{x}^{\prime \prime \prime} \int_{A} E z \phi \mathrm{d} A \\
& =G A \gamma_{z}+E I_{y \phi} \theta_{x}^{\prime \prime \prime}=G A \gamma_{z},
\end{aligned}
$$

missä

$$
G A=\int_{A} G \mathrm{~d} A
$$


on leikkausjäykkyys, joka homogeenisen poikkileikkauksen tapauksessa on liukumoduulin $G$ ja poikkipinnan alan $A$ tulo. Sovellettiin heikon muodon yhtälöitä (22a) ja (22b), joissa ensin $\hat{\Phi}=y, \hat{\Psi}_{x}=y$ ja sitten $\hat{\Phi}=z, \hat{\Psi}_{x}=z$, sekä otettiin lopuksi huomioon yhteydet (51b) ja (51c). Yhteydet (58) leikkausvoimien $Q_{y}$ ja $Q_{z}$ sekä keskimääräisten liukumien $\gamma_{y}$ ja $\gamma_{z}$ välillä ovat varsin pelkistetyt ja niitä pyritään siksi parantamaan. Vastaavassa tilanteessa yksiakselisen taivutuksen Timoshenko palkkiteoriassa [5] ( $x, y$-tasossa, jolloin $Q=Q_{y}$ ja $\gamma=\gamma_{y}$ ) yhteyttä $Q=G A \gamma$ on totuttu parantamaan muotoon $Q=k G A \gamma$, missä $k$ on leikkauskorjauskerroin. Toimitaan myös tässä Timoshenko palkkiteorian hengessä ja otetaan leikkausvoimille ja keskimääräisille liukumille lineaarinen riippuvuus. Se esitetään muodossa

$$
\left\{\begin{array}{l}
Q_{y} \\
Q_{z}
\end{array}\right\}=G A\left[\begin{array}{cc}
k_{y} & k_{y z} \\
k_{z y} & k_{z}
\end{array}\right]\left\{\begin{array}{c}
\gamma_{y} \\
\gamma_{z}
\end{array}\right\},
$$

missä vakioita $k_{y}, k_{y z}, k_{z y}$ ja $k_{z}$ kutsutaan leikkauskorjauskertoimiksi.

Seuraavassa johdetaan kaavat leikkauskorjauskertoimien määrittämiseksi. Johto suoritetaan tarkastelemalla taivutettua sauvaa, jossa ei esiinny vääntöä eli $\theta_{x}^{\prime}=0$. Leikkauksen osuus sauvan sisäisestä virtuaalisesta työstä on

$$
\delta W_{\text {int }}^{s}=-\int_{x_{1}}^{x_{2}}\left(\int_{A}\left\{\begin{array}{l}
\delta \gamma_{y x} \\
\delta \gamma_{z x}
\end{array}\right\}^{T}\left\{\begin{array}{c}
\tau_{y x} \\
\tau_{z x}
\end{array}\right\} \mathrm{d} A\right) \mathrm{d} x .
$$

Käyttäen virtuaalisten liukumien lausekkeita (26b) ja (26c), kun $\delta \theta_{x}^{\prime}=0$, saadaan tästä

$$
\left.\delta W_{\text {int }}^{s}=-\int_{x_{1}}^{x_{2}}\left\{\begin{array}{l}
\delta \gamma_{y} \\
\delta \gamma_{z}
\end{array}\right\}^{T} \int_{A}\left\{\begin{array}{c}
\tau_{y x} \\
\tau_{z x}
\end{array}\right\} \mathrm{d} A\right) \mathrm{d} x=-\int_{x_{1}}^{x_{2}}\left\{\begin{array}{c}
\delta \gamma_{y} \\
\delta \gamma_{z}
\end{array}\right\}^{T}\left\{\begin{array}{l}
Q_{y} \\
Q_{z}
\end{array}\right\} \mathrm{d} x .
$$

Sijoittamalla tähän leikkausvoimien lauseke (60) saadaan

$$
\delta W_{\text {int }}^{s}=-\int_{x_{1}}^{x_{2}}\left\{\begin{array}{l}
\delta \gamma_{y} \\
\delta \gamma_{z}
\end{array}\right\}^{T} G A\left[\begin{array}{cc}
k_{y} & k_{y z} \\
k_{z y} & k_{z}
\end{array}\right]\left\{\begin{array}{l}
\gamma_{y} \\
\gamma_{z}
\end{array}\right\} \mathrm{d} x .
$$

Määritetään vastaavasti sisäisen virtuaalisen työn lauseke (61) ottamalla virtuaalisiksi liukumiksi kaavojen (15b) ja (15c) mukaiset tarkemmat lausekkeet, jotka puhtaan taivutuksen tapauksessa $\left(\delta \theta_{x}^{\prime}=0, \delta \theta_{x}^{\prime \prime \prime}=0\right)$ ovat

Saadaan

$$
\left\{\begin{array}{l}
\delta \gamma_{x y} \\
\delta \gamma_{x z}
\end{array}\right\}=-\left[\begin{array}{cc}
\frac{\partial \Psi_{y}}{\partial y} & \frac{\partial \Psi_{z}}{\partial y} \\
\frac{\partial \Psi_{y}}{\partial z} & \frac{\partial \Psi_{z}}{\partial z}
\end{array}\right]\left\{\begin{array}{c}
\delta \theta_{z}^{\prime \prime} \\
\delta \theta_{y}^{\prime \prime}
\end{array}\right\} .
$$

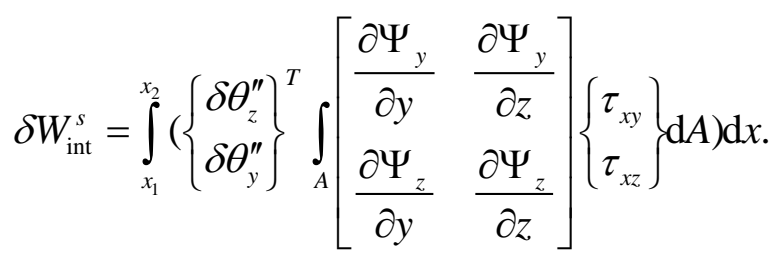

Sijoittamalla tähän leikkausjännitysten lausekkeet (18b) ja (18c), joissa $\left(\theta_{x}^{\prime}=0, \theta_{x}^{\prime \prime \prime}=0\right)$, eli

saadaan

$$
\left\{\begin{array}{c}
\tau_{x y} \\
\tau_{x z}
\end{array}\right\}=-G\left[\begin{array}{cc}
\frac{\partial \Psi_{y}}{\partial y} & \frac{\partial \Psi_{z}}{\partial y} \\
\frac{\partial \Psi_{y}}{\partial z} & \frac{\partial \Psi_{z}}{\partial z}
\end{array}\right]\left\{\begin{array}{c}
\theta_{z}^{\prime \prime} \\
\theta_{y}^{\prime \prime}
\end{array}\right\}
$$




$$
\begin{aligned}
\delta W_{\text {int }}^{s} & \left.=-\int_{x_{1}}^{x_{2}}\left\{\begin{array}{l}
\delta \theta_{z}^{\prime \prime} \\
\delta \theta_{y}^{\prime \prime}
\end{array}\right\}_{A}^{T} \int_{A} G\left[\begin{array}{ll}
\frac{\partial \Psi_{y}}{\partial y} \frac{\partial \Psi_{y}}{\partial y}+\frac{\partial \Psi_{y}}{\partial z} \frac{\partial \Psi_{y}}{\partial z} & \frac{\partial \Psi_{y}}{\partial y} \frac{\partial \Psi_{z}}{\partial y}+\frac{\partial \Psi_{y}}{\partial z} \frac{\partial \Psi_{z}}{\partial z} \\
\frac{\partial \Psi_{z}}{\partial y} \frac{\partial \Psi_{y}}{\partial y}+\frac{\partial \Psi_{z}}{\partial z} \frac{\partial \Psi_{y}}{\partial z} & \frac{\partial \Psi_{z}}{\partial y} \frac{\partial \Psi_{z}}{\partial y}+\frac{\partial \Psi_{z}}{\partial z} \frac{\partial \Psi_{z}}{\partial z}
\end{array}\right] \mathrm{d} A\left\{\begin{array}{c}
\theta_{z}^{\prime \prime} \\
\theta_{y}^{\prime \prime}
\end{array}\right\}\right) \mathrm{d} x \\
& =-\int_{x_{1}}^{x_{2}}\left(\left\{\begin{array}{l}
\delta \theta_{z}^{\prime \prime} \\
\delta \theta_{y}^{\prime \prime}
\end{array}\right\}_{A}^{T}\left[\begin{array}{ll}
E y \Psi_{y} & E z \Psi_{y} \\
E y \Psi_{z} & E z \Psi_{z}
\end{array}\right] d A\left\{\begin{array}{l}
\theta_{z}^{\prime \prime} \\
\theta_{y}^{\prime \prime}
\end{array}\right\}\right) \mathrm{d} x .
\end{aligned}
$$

Lopuksi sovellettiin heikon muodon kaavoja (22c) ja (22d), kun $\hat{\Psi}_{y}=\Psi_{y}$ ja $\hat{\Psi}_{z}=\Psi_{z}$. Tarkempiin liukuma- ja leikkausjännitysjakaumiin (15) ja (18) perustuva sisäisen virtuaalisen työn lauseke saa siten muodon

$$
\delta W_{\text {int }}^{s}=-\int_{x_{1}}^{x_{2}}\left\{\begin{array}{c}
\delta \theta_{z}^{\prime \prime} \\
\delta \theta_{y}^{\prime \prime}
\end{array}\right\}^{T}\left[\begin{array}{ll}
E I_{y \Psi_{y}} & E I_{z \Psi_{y}} \\
E I_{y \Psi_{z}} & E I_{z \Psi_{z}}
\end{array}\right]\left\{\begin{array}{c}
\theta_{z}^{\prime \prime} \\
\theta_{y}^{\prime \prime}
\end{array}\right\} d x
$$

missä

$$
E I_{y \Psi_{y}}=\int_{A} E y \Psi_{y} \mathrm{~d} A, \quad E I_{z \Psi_{y}}=E I_{y \Psi_{z}}=\int_{A} E z \Psi_{y} \mathrm{~d} A=\int_{A} E y \Psi_{z} \mathrm{~d} A, \quad E I_{z \Psi_{z}}=\int_{A} E z \Psi_{z} \mathrm{~d} A
$$

Leikkauskorjauskertoimet määritetään vaatimalla virtuaalisen työn lausekkeiden (67) ja (68) olevan yhtäsuuret. Saadaan yhtälö

$$
\left\{\begin{array}{l}
\delta \gamma_{y} \\
\delta \gamma_{z}
\end{array}\right\}^{T} G A\left[\begin{array}{cc}
k_{y} & k_{y z} \\
k_{z y} & k_{z}
\end{array}\right]\left\{\begin{array}{l}
\gamma_{y} \\
\gamma_{z}
\end{array}\right\}=\left\{\begin{array}{c}
\delta \theta_{z}^{\prime \prime} \\
\delta \theta_{y}^{\prime \prime}
\end{array}\right\}^{T}\left[\begin{array}{cc}
E I_{y \Psi_{y}} & E I_{z \Psi_{y}} \\
E I_{y \Psi_{z}} & E I_{z \Psi_{z}}
\end{array}\right]\left\{\begin{array}{c}
\theta_{z}^{\prime \prime} \\
\theta_{y}^{\prime \prime}
\end{array}\right\} .
$$

Soveltamalla yhtälöitä (C.2) sekä virtuaalisille että todellisille suureille saadaan tästä

$$
\left\{\begin{array}{l}
\delta \theta_{z}^{\prime \prime} \\
\delta \theta_{y}^{\prime \prime}
\end{array}\right\}^{T}\left(\left[\begin{array}{cc}
E I_{z} & E I_{y z} \\
E I_{y z} & E I_{y}
\end{array}\right] \frac{1}{G A}\left[\begin{array}{cc}
k_{y} & k_{y z} \\
k_{z y} & k_{z}
\end{array}\right]^{-1}\left[\begin{array}{cc}
E I_{z} & E I_{y z} \\
E I_{y z} & E I_{y}
\end{array}\right]-\left[\begin{array}{cc}
E I_{y \Psi_{y}} & E I_{z \Psi_{y}} \\
E I_{y \Psi_{z}} & E I_{z \Psi_{z}}
\end{array}\right]\right)\left\{\begin{array}{l}
\theta_{z}^{\prime \prime} \\
\theta_{y}^{\prime \prime}
\end{array}\right\}=0,
$$

josta seuraa leikkauskorjauskertoimille tulos

$$
\left[\begin{array}{cc}
k_{y} & k_{y z} \\
k_{z y} & k_{z}
\end{array}\right]=\frac{1}{G A}\left[\begin{array}{cc}
E I_{z} & E I_{y z} \\
E I_{y z} & E I_{y}
\end{array}\right]\left[\begin{array}{cc}
E I_{y \Psi_{y}} & E I_{z \Psi_{y}} \\
E I_{y \Psi_{z}} & E I_{z \Psi_{z}}
\end{array}\right]^{-1}\left[\begin{array}{cc}
E I_{z} & E I_{y z} \\
E I_{y z} & E I_{y}
\end{array}\right] .
$$

Todetaan, että $k_{y z}=k_{z y}$. Leikkausvoimien ja keskimääräisten liukumien yhteydet (60) ja leikkauskorjauskertoimien määrityskaava (72) antavat mahdollisuuden yleistää Timoshenko palkkiteoria luontevasti kaksiakseliseen taivutukseen.

\subsection{Vääntömomentti ja Saint-Venantin vääntömomentti}

Soveltamalla vääntömomentin määrittelykaavaa (33f) ja leikkausjännitysten lausekkeita (18b) ja (18c) saadaan 


$$
\begin{aligned}
M_{x} & =\theta_{x}^{\prime} \int_{A} G\left[-\left(\frac{\partial \Phi}{\partial y}-z\right)\left(z-z_{\mathrm{T}}\right)+\left(\frac{\partial \Phi}{\partial z}+y\right)\left(y-y_{\mathrm{T}}\right)\right] \mathrm{d} A \\
& +\theta_{x}^{\prime \prime \prime} \int_{A} G\left[-\frac{\partial \Psi_{x}}{\partial y}\left(z-z_{\mathrm{T}}\right)+\frac{\partial \Psi_{x}}{\partial z}\left(y-y_{\mathrm{T}}\right)\right] \mathrm{d} A \\
& -\theta_{z}^{\prime \prime} \int_{A} G\left[-\frac{\partial \Psi_{y}}{\partial y}\left(z-z_{\mathrm{T}}\right)+\frac{\partial \Psi_{y}}{\partial z}\left(y-y_{\mathrm{T}}\right)\right] \mathrm{d} A \\
& -\theta_{y}^{\prime \prime} \int_{A} G\left[-\frac{\partial \Psi_{z}}{\partial y}\left(z-z_{\mathrm{T}}\right)+\frac{\partial \Psi_{z}}{\partial z}\left(y-y_{\mathrm{T}}\right)\right] \mathrm{d} A .
\end{aligned}
$$

Tämä saa liitteen E perusteella muodon

$$
M_{x}=G J \theta_{x}^{\prime}-E I_{\phi} \theta_{x}^{\prime \prime \prime}
$$

missä

$$
G J=\int_{A} G\left[-\left(\frac{\partial \Phi}{\partial y}-z\right) z+\left(\frac{\partial \Phi}{\partial z}+y\right) y\right] \mathrm{d} A .
$$

Niinsanotussa Saint-Venantin vääntöteoriassa vääntömomentin $M_{x}$ ja vääntymän $\theta_{x}^{\prime}$ yhteys on muotoa $M_{x}=G J \theta_{x}^{\prime}$, missä $G J$ on kaavan (75) mukainen. Tämän vuoksi suuretta

$$
T=G J \theta_{x}^{\prime}
$$

kutsutaan Saint-Venantin vääntömomentiksi. Suuretta GJ kutsutaan vääntöjäykkyydeksi ja homogeenisen poikkileikkauksen tapauksessa suuretta $J$ vääntöjäyhyysmomentiksi. Kaavojen (74), (76) ja (54c) perusteella saadaan vääntömomentille tulos

$$
M_{x}=T+B^{\prime} .
$$

\section{Sauvatehtävän differentiaaliyhtälöistä}

\subsection{Differentiaaliyhtälöiden johto}

Tutkitaan nyt millaisiksi palkin siirtymäformulaation mukaiset differentiaaliyhtälöt muodostuvat. Derivoimalla yhtälöt (44b) ja (44c) puolittain ja sijoittamalla niihin (44d) ja (44e) sekä ottamalla samalla käyttöön osittainen matriisiesitys tasapainoyhtälöt saadaan muotoon

$$
\begin{aligned}
& N^{\prime}+q_{x}=0, \\
& \left\{\begin{array}{l}
M_{z}^{\prime \prime} \\
M_{y}^{\prime \prime}
\end{array}\right\}+\left\{\begin{array}{l}
q_{y} \\
q_{z}
\end{array}\right\}+\left\{\begin{array}{l}
m_{z}^{\prime} \\
m_{y}^{\prime}
\end{array}\right\}=\left\{\begin{array}{l}
0 \\
0
\end{array}\right\}, \\
& \left\{\begin{array}{l}
Q_{y}^{\prime} \\
Q_{z}^{\prime}
\end{array}\right\}+\left\{\begin{array}{l}
q_{y} \\
q_{z}
\end{array}\right\}=\left\{\begin{array}{l}
0 \\
0
\end{array}\right\}, \\
& M_{x}^{\prime}+m_{x}+b^{\prime}=0 .
\end{aligned}
$$

Sijoittamalla jännitysresultanttien lausekkeet (54) ja (60) tasapainoyhtälöihin (78) sekä käyttämällä yhteyksiä (14) ja (74) saadaan 


$$
\begin{aligned}
& E A u^{\prime \prime}+q_{x}=0, \\
& {\left[\begin{array}{cc}
E I_{z} & E I_{y z} \\
E I_{y z} & E I_{y}
\end{array}\right]\left\{\begin{array}{l}
\theta_{z}^{\prime \prime \prime} \\
\theta_{y}^{\prime \prime \prime}
\end{array}\right\}=\left\{\begin{array}{l}
q_{y} \\
q_{z}
\end{array}\right\}+\left\{\begin{array}{l}
m_{z}^{\prime} \\
m_{y}^{\prime}
\end{array}\right\},} \\
& G A\left[\begin{array}{cc}
k_{y} & k_{y z} \\
k_{z y} & k_{z}
\end{array}\right]\left\{\begin{array}{c}
v^{\prime \prime}-\theta_{z}^{\prime} \\
w^{\prime \prime}-\theta_{y}^{\prime}
\end{array}\right\}+\left\{\begin{array}{l}
q_{y} \\
q_{z}
\end{array}\right\}=\left\{\begin{array}{l}
0 \\
0
\end{array}\right\}, \\
& E I_{\phi} \theta_{x}^{(4)}-G J \theta_{x}^{\prime \prime}=m_{x}+b^{\prime} .
\end{aligned}
$$

Ensimmäinen yhtälö (79a) on toisen kertaluvun tavallinen differentiaaliyhtälö, jossa on tuntemattomana aksiaalinen siirtymä $u(x)$. Keskimmäiset yhtälöt (79b) ja (79c) muodostavat neljän yhtälön ryhmän, joissa tuntemattomina ovat vääntökeskiön poikittaiset siirtymät $v(x)$ ja $w(x)$ sekä poikkileikkauksen rotaatiot $\theta_{z}(x)$ ja $\theta_{y}(x)$. Viimeinen yhtälö (79d) on neljännen kertaluvun tavallinen differentiaaliyhtälö, jossa on tuntemattomana vääntökulma $\theta_{x}(x)$. Havaitaan, että veto/puristustehtävä, taivutustehtävä ja vääntötehtävä voidaan ratkaista erikseen.

Muokataan taivutustehtävän yhtälöitä (79b) ja (79c) edelleen. Ratkaisemalla yhtälöistä (79c) $\theta_{z}^{\prime}$ ja $\theta_{y}^{\prime}$ saadaan

$$
\left\{\begin{array}{l}
\theta_{z}^{\prime} \\
\theta_{y}^{\prime}
\end{array}\right\}=\left\{\begin{array}{l}
v^{\prime \prime} \\
w^{\prime \prime}
\end{array}\right\}+\frac{1}{G A}\left[\begin{array}{cc}
k_{y} & k_{y z} \\
k_{z y} & k_{z}
\end{array}\right]^{-1}\left\{\begin{array}{l}
q_{y} \\
q_{z}
\end{array}\right\} .
$$

Derivoimalla tämä puolittain kahdesti ja sijoittamalla yhtälöön (79b) saadaan

Merkitsemällä

$$
\left\{\begin{array}{c}
v^{(4)} \\
w^{(4)}
\end{array}\right\}=\left[\begin{array}{cc}
E I_{z} & E I_{y z} \\
E I_{y z} & E I_{y}
\end{array}\right]^{-1}\left(\left\{\begin{array}{l}
q_{y} \\
q_{z}
\end{array}\right\}+\left\{\begin{array}{l}
m_{z}^{\prime} \\
m_{y}^{\prime}
\end{array}\right\}\right)-\frac{1}{G A}\left[\begin{array}{cc}
k_{y} & k_{y z} \\
k_{z y} & k_{z}
\end{array}\right]^{-1}\left\{\begin{array}{l}
q_{y}^{\prime \prime} \\
q_{z}^{\prime \prime}
\end{array}\right\} .
$$

$$
\left\{\begin{array}{l}
f_{y} \\
f_{z}
\end{array}\right\}=\left[\begin{array}{cc}
E I_{z} & E I_{y z} \\
E I_{y z} & E I_{y}
\end{array}\right]^{-1}\left(\left\{\begin{array}{l}
q_{y} \\
q_{z}
\end{array}\right\}+\left\{\begin{array}{l}
m_{z}^{\prime} \\
m_{y}^{\prime}
\end{array}\right\}\right)-\frac{1}{G A}\left[\begin{array}{cc}
k_{y} & k_{y z} \\
k_{z y} & k_{z}
\end{array}\right]^{-1}\left\{\begin{array}{l}
q_{y}^{\prime \prime} \\
q_{z}^{\prime \prime}
\end{array}\right\}
$$

nähdään, että yhtälöt (81) ovat kaksi erillistä neljännen kertaluvun differentiaaliyhtälöä

$$
v^{(4)}=f_{y}(x), \quad w^{(4)}=f_{z}(x),
$$

jotka on helppo ratkaista. Kun poikittaiset siirtymät on ratkaistu, voidaan rotaatiot $\theta_{z}(x)$ ja $\theta_{y}(x)$ määrittää integroimalla ensimmäisen kertaluvun differentiaaliyhtälöt (80).

\subsection{Perustelua paikallisen tarkastelun otaksumiin}

Kohdassa 1.3 esitettiin, että suoritettaessa tiettyyn poikkileikkaukseen liittyviä paikallisia tarkasteluja, voidaan jakautuneen kuormituksen vaikutus tasapainoyhtälöissä (44) jättää huomiotta. Tämä merkitsee, että tasapainoyhtälöissä ja vastaavasti palkin differentiaaliyhtälöissä voidaan merkitä $q_{x}=0, q_{y}=0, q_{z}=0, m_{x}=0, m_{y}=0, m_{z}=0, b=0$. Yhtälöt (79a), (83), (80) ja (79d) saavat siten muodon

$$
u^{\prime \prime}=0, v^{(4)}=0, w^{(4)}=0, \theta_{z}^{\prime}=v^{\prime \prime}, \theta_{y}^{\prime}=w^{\prime \prime}, \quad E I_{\phi} \theta_{x}^{(4)}-G J \theta_{x}^{\prime \prime}=0 .
$$

Yhtälön (84a) ratkaisu $u(x)$ on ensimmäisen asteen polynomi ja yhtälöiden (84b) ja (84c) ratkaisut $v(x)$ ja $w(x)$ ovat kolmannen asteen polynomeja. Yhtälöistä (84d) ja (84e) seuraa $\theta_{z}=v^{\prime}+C_{1}$ ja $\theta_{y}=w^{\prime}+C_{2}$, joten $\theta_{z}(x)$ ja $\theta_{y}(x)$ ovat toisen asteen polynomeja. Näin pystyttiin perustelemaan kohdassa 1.3 esitetyt siirtymien $u(x), v(x), w(x)$ ja rotaatioiden 
$\theta_{z}(x)$ ja $\theta_{y}(x)$ polynomiapproksimaatioiden asteluvut. Yhtälön (84f) ratkaisu $\theta_{x}(x)$ sensijaan ei ole polynomimuotoinen. Tämän vuoksi kohdassa 1.3 tehtyä vääntökulman $\theta_{x}(x)$ paikallisen approksimaation valitsemista kuubiseksi ei voida perustella tällä tavoin.

\section{Poikkileikkauksen jännitysjakauman määrittäminen}

Kun palkin poikkileikkauksen käyristymisfunktiot $\Phi(y, z), \Psi_{x}(y, z), \Psi_{y}(y, z)$ ja $\Psi_{z}(y, z)$ on ratkaistu reuna-arvoprobleemista (21) ja palkin siirtymäsuureet $u(x), v(x), w(x), \theta_{x}(x)$, $\theta_{y}(x)$ ja $\theta_{z}(x)$ on ratkaistu esimerkiksi differentiaaliyhtälöistä (79a) (83), (80) ja (79d), voidaan tietyn poikkileikkauksen $x=x_{0}$ jännitysjakaumat määrittää käyttäen yhtälöitä (18), jotka ovat sopivassa matriisimuodossa

$$
\begin{aligned}
& \sigma_{x}=E\left(u^{\prime}-\left\{\begin{array}{l}
\theta_{z}^{\prime} \\
\theta_{y}^{\prime}
\end{array}\right\}^{T}\left\{\begin{array}{l}
y \\
z
\end{array}\right\}+\theta_{x}^{\prime \prime} \phi\right), \\
& \left\{\begin{array}{c}
\tau_{y x} \\
\tau_{z x}
\end{array}\right\}=G\left(\theta_{x}^{\prime}\left\{\begin{array}{l}
\frac{\partial \Phi}{\partial y}-z \\
\frac{\partial \Phi}{\partial z}+y
\end{array}\right\}+\theta_{x}^{\prime \prime \prime}\left\{\begin{array}{c}
\frac{\partial \Psi_{x}}{\partial y} \\
\frac{\partial \Psi_{x}}{\partial z}
\end{array}\right\}-\left[\begin{array}{cc}
\frac{\partial \Psi_{y}}{\partial y} & \frac{\partial \Psi_{z}}{\partial y} \\
\frac{\partial \Psi_{y}}{\partial z} & \frac{\partial \Psi_{z}}{\partial z}
\end{array}\right]\left\{\begin{array}{c}
\theta_{z}^{\prime \prime} \\
\theta_{y}^{\prime \prime}
\end{array}\right\}\right) .
\end{aligned}
$$

Niissä $\quad u^{\prime}=u^{\prime}\left(x_{0}\right), \quad \theta_{x}^{\prime}=\theta_{x}^{\prime}\left(x_{0}\right), \quad \theta_{x}^{\prime \prime}=\theta_{x}^{\prime \prime}\left(x_{0}\right), \quad \theta_{x}^{\prime \prime \prime}=\theta_{x}^{\prime \prime \prime}\left(x_{0}\right), \quad \theta_{y}^{\prime}=\theta_{y}^{\prime}\left(x_{0}\right), \quad \theta_{y}^{\prime \prime}=\theta_{y}^{\prime \prime}\left(x_{0}\right)$ $\theta_{z}^{\prime}=\theta_{z}^{\prime}\left(x_{0}\right)$ ja $\theta_{z}^{\prime \prime}=\theta_{z}^{\prime \prime}\left(x_{0}\right)$.

Yhtälöissä (85) esiintyvät siirtymäsuureiden derivaatat $u^{\prime}, \theta_{x}^{\prime}, \theta_{x}^{\prime \prime}, \theta_{y}^{\prime}$ ja $\theta_{z}^{\prime}$ voidaan ratkaista jännitysresultanttien avulla yhtälöistä (54) ja (76). Derivoimalla vielä $\theta_{x}^{\prime \prime}$ :n, $\theta_{y}^{\prime}$ :n ja $\theta_{z}^{\prime}:$ n lausekkeet puolittain sekä soveltamalla tasapainoyhtälöitä (56) saadaan

$$
\begin{aligned}
& u^{\prime}=\frac{N}{E A}, \theta_{x}^{\prime}=\frac{T}{G J}, \theta_{x}^{\prime \prime}=-\frac{B}{E I_{\phi}}, \theta_{x}^{\prime \prime \prime}=-\frac{B^{\prime}}{E I_{\phi}}, \\
& \left\{\begin{array}{l}
\theta_{z}^{\prime} \\
\theta_{y}^{\prime}
\end{array}\right\}=-\left[\begin{array}{cc}
E I_{z} & E I_{y z} \\
E I_{y z} & E I_{y}
\end{array}\right]^{-1}\left\{\begin{array}{l}
M_{z} \\
M_{y}
\end{array}\right\},\left\{\begin{array}{l}
\theta_{z}^{\prime \prime} \\
\theta_{y}^{\prime \prime}
\end{array}\right\}=-\left[\begin{array}{cc}
E I_{z} & E I_{y z} \\
E I_{y z} & E I_{y}
\end{array}\right]^{-1}\left\{\begin{array}{l}
Q_{y} \\
Q_{z}
\end{array}\right\} .
\end{aligned}
$$

Sijoittamalla tulokset (86) lausekkeisiin (85) saadaan jännitykset lausutuiksi jännitysresultanttien avulla seuraavasti

$$
\begin{aligned}
& \sigma_{x}=E\left(\frac{N}{E A}+\left\{\begin{array}{l}
M_{z} \\
M_{y}
\end{array}\right\}^{T}\left[\begin{array}{cc}
E I_{z} & E I_{y z} \\
E I_{y z} & E I_{y}
\end{array}\right]^{-1}\left\{\begin{array}{l}
y \\
z
\end{array}\right\}-\frac{B}{E I_{\phi}} \phi\right), \\
& \left\{\begin{array}{l}
\tau_{y x} \\
\tau_{z x}
\end{array}\right\}=G\left(\frac{T}{G J}\left\{\begin{array}{l}
\frac{\partial \Phi}{\partial y}-z \\
\frac{\partial \Phi}{\partial z}+y
\end{array}\right\}-\frac{B^{\prime}}{E I_{\phi}}\left\{\begin{array}{c}
\frac{\partial \Psi_{x}}{\partial y} \\
\frac{\partial \Psi_{x}}{\partial z}
\end{array}\right\}+\left[\begin{array}{cc}
\frac{\partial \Psi_{y}}{\partial y} & \frac{\partial \Psi_{z}}{\partial y} \\
\frac{\partial \Psi_{y}}{\partial z} & \frac{\partial \Psi_{z}}{\partial z}
\end{array}\right]\left[\begin{array}{cc}
E I_{z} & E I_{y z} \\
E I_{y z} & E I_{y}
\end{array}\right]^{-1}\left\{\begin{array}{l}
Q_{y} \\
Q_{z}
\end{array}\right\}\right) .
\end{aligned}
$$

Siinä tapauksessa, että $y, z$-koordinaatisto yhtyy poikileikkauksen pääjäykkyyskoordinaatistoon $\left(E I_{y z}=0\right)$, yhtälöt (87) saavat yksinkertaisemman muodon 


$$
\begin{aligned}
& \sigma_{x}=E\left(\frac{N}{E A}+\frac{M_{z}}{E I_{z}} y+\frac{M_{y}}{E I_{y}} z-\frac{B}{E I_{\phi}} \phi\right), \\
& \tau_{y x}=G\left[\frac{T}{G J}\left(\frac{\partial \Phi}{\partial y}-z\right)-\frac{B^{\prime}}{E I_{\phi}} \frac{\partial \Psi_{x}}{\partial y}+\frac{Q_{y}}{E I_{z}} \frac{\partial \Psi_{y}}{\partial y}+\frac{Q_{z}}{E I_{y}} \frac{\partial \Psi_{z}}{\partial y}\right], \\
& \tau_{z x}=G\left[\frac{T}{G J}\left(\frac{\partial \Phi}{\partial z}+y\right)-\frac{B^{\prime}}{E I_{\phi}} \frac{\partial \Psi_{x}}{\partial z}+\frac{Q_{y}}{E I_{z}} \frac{\partial \Psi_{y}}{\partial z}+\frac{Q_{z}}{E I_{y}} \frac{\partial \Psi_{z}}{\partial z}\right] .
\end{aligned}
$$

Tarkastellaan lopuksi kaavojen (88) ja liitteessä F esitettyjen avointen ohutseinämäisten poikkileikkausten jännitysten kaavojen (F.13) ja (F.14) yhtäläisyyksiä. Homogeenisen poikkileikkauksen tapauksessa normaalijännityksen kaava (88a) saa muodon

$$
\sigma_{x}=\frac{N}{A}+\frac{M_{z}}{I_{z}} y+\frac{M_{y}}{I_{y}} z-\frac{B}{I_{\phi}} \phi .
$$

Kaava (F.13) poikkeaa kaavasta (89) siinä, että käyristymisjäyhyysmomentin $I_{\phi}$ paikalla on sektoriaalinen jäyhyysmometti $I_{\omega}$ ja käyristymisfunktion $\phi(y, z)$ paikalla normeerattu sektoriaaalinen koordinaatti $\omega_{\mathrm{T}}(s)$ vääntökeskiön suhteen. Leikkausjännityksien kohdalla Saint-Venantin väännön osuus jätetään yksinkertaisuuden vuoksi tarkastelun ulkopuolelle. Homogeenisen poikkileikkauksen tapauksessa leikkausjännitysten kaavat (88b) ja (88c) ilman Saint-Venantin vääntömomentin $T$ sisältävää termiä ovat

$$
\begin{aligned}
& \tau_{y x}=\frac{Q_{y}}{I_{z}} \frac{G}{E} \frac{\partial \Psi_{y}}{\partial y}+\frac{Q_{z}}{I_{y}} \frac{G}{E} \frac{\partial \Psi_{z}}{\partial y}-\frac{B^{\prime}}{I_{\phi}} \frac{G}{E} \frac{\partial \Psi_{x}}{\partial y}, \\
& \tau_{z x}=\frac{Q_{y}}{I_{z}} \frac{G}{E} \frac{\partial \Psi_{y}}{\partial z}+\frac{Q_{z}}{I_{y}} \frac{G}{E} \frac{\partial \Psi_{z}}{\partial z}-\frac{B^{\prime}}{I_{\phi}} \frac{G}{E} \frac{\partial \Psi_{x}}{\partial z} .
\end{aligned}
$$

Tarkastellaan leikkausjännityskomponenttia $\tau_{s x}$ ohutseinämäisen poikkileikkauksen keskiviivalla $y=y(s), z=z(s)$. Sauvateorian jännitysotaksumien (1) vallitessa sille on voimassa

$$
\tau_{s x}=\frac{\mathrm{d} y}{\mathrm{~d} s} \tau_{y x}+\frac{\mathrm{d} z}{\mathrm{~d} s} \tau_{z x}
$$

Käyttäen kaavoja (90) ja (91) saadaan

$$
\tau_{s x}=\frac{Q_{y}}{I_{z}} \frac{G}{E} \frac{\partial \Psi_{y}}{\partial s}+\frac{Q_{z}}{I_{y}} \frac{G}{E} \frac{\partial \Psi_{z}}{\partial s}-\frac{B^{\prime}}{I_{\phi}} \frac{G}{E} \frac{\partial \Psi_{X}}{\partial s} .
$$

Kaava (F.14) poikkeaa nyt kaavasta (92) siinä, että käyristymisjäyhyysmomentin $I_{\phi}$ paikalla on sektoriaalinen jäyhyysmometti $I_{\omega}$ ja

$$
\frac{G}{E} \frac{\partial \Psi_{y}}{\partial s} \triangleq \frac{\tilde{S}_{z}}{t}, \quad \frac{G}{E} \frac{\partial \Psi_{z}}{\partial s} \triangleq \frac{\tilde{S}_{y}}{t}, \quad \frac{G}{E} \frac{\partial \Psi_{x}}{\partial s} \triangleq \frac{\tilde{S}_{\omega}}{t},
$$

missä merkki $\triangleq$ tarkoittaa vastaavuutta. Kaavoissa (93) $\tilde{S}_{y}(s), \tilde{S}_{z}(s)$ ja $\tilde{S}_{\omega}(s)$ ovat osapoikkipinnan staattiset momentit ja $t(s)$ on poikkileikkauksen paksuus.

\section{Johtopäätökset}

Artikkelissa on esitetty teoria, jonka avulla voidaan määrittää taivutetun ja väännetyn suoran sauvan siirtymä- ja jännitystila systemaattisesti ja perinteisiä teorioita tarkemmin. Sauvan poikkileikkaus voi olla muodoltaan mielivaltainen ja koostua myös useammasta materiaalista. Oleellisena osana teoriaa on poikkileikkaukseen liittyvien reuna-arvotehtävien mukanaolo. 
Nykyaikaisten tehokkaiden elemettimenetelmäohjelmistojen johdosta nämä lisätehtävät eivät aiheuta ongelmia. Samaan tapaan kuin perinteisissä sauvateorioissa veto/puristus-, taivutus- ja vääntötehtävät voidaan käsitellä erikseen. Taivutuksen yhtälöissä leikkausmuodonmuutoksen vaikutus otetaan huomioon Timoshenkon palkkiteoriaa muistuttavalla käsittelytavalla, johon liittyville leikkauskorjauskertoimille on johdettu kaavat. Väännön yhtälöt muistuttavat monessa suhteessa avointen ohutseinämäisten sauvojen väännön yhtälöitä. Keskeisin eroavaisuus on siinä, että ohutseinämäisen poikkileikkauksen sektoriaalista koordinaattia $\Omega_{0}(s)$ origon $\mathrm{O}$ suhteen (nollapiste $\mathrm{P}_{0}$ ) ja normeerattua sektoriaalista koordinaattia $\omega_{\mathrm{T}}(s)$ vääntökeskiön T suhteen vastaavat tässä teoriassa käyristymisfunktio $\Psi(y, z)$ (nollapiste $\mathrm{P}_{0}$ ) ja käyristymisfunktio $\psi(y, z)$. Koska sektoriaalinen koordinaatti on vain ohutseinämäiseen poikkileikkaukseen liittyvä suure, mutta käyristymisfunktio voidaan määrittää mielivaltaisen muotoiselle poikkileikkaukselle, voidaan esitettyä teoriaa pitää avointen ohutseinämäisten sauvojen taivutus- ja vääntöteorian yleistyksenä. Se soveltuu kaikentyyppisille, myös eri materiaaleista koostuville, poikkileikkauksille ja huomioi leikkausmuodonmuutoksen vaikutuksen taipumaan. Poikkileikkaus voi olla täysi tai ontto, paksu- tai ohutseinämäinen ja avoin tai suljettu.

\section{Kiitokset}

Kiitokset em. prof. Eero-Matti Saloselle, joka on vuosien varrella useaan otteeseen tuonut esille ajatuksen mahdollisuudesta kehittää teoria, jolla sauvan vääntötehtävä voitaisiin käsitellä poikkileikkauksen tyypistä riippumatta yhtenäisellä tavalla. Hänen lukuisat työn varrella antamansa kommentit ja parannusehdotukset ovat mahdollistaneet tämän artikkelin syntymisen. Kiitokset myös artikkelin arvioijille perusteellisesta työstä. 
Liite A: Kaavojen (6) johto

Otaksutaan, että poikkileikkaus kohdassa $x$ siirtyy jäykän kappaleen pienen siirtymän liikkeen mukaisesti. Valitaan siirtopisteeksi poikkileikkauksen piste T. Poikkileikkauksen yleisen pisteen siirtymävektorille

$$
\mathbf{u}^{\mathrm{R}}(x, y, z)=u_{x}^{\mathrm{R}}(x, y, z) \mathbf{i}+u_{y}^{\mathrm{R}}(x, y, z) \mathbf{j}+u_{z}^{\mathrm{R}}(x, y, z) \mathbf{k}
$$

saadaan

$$
\mathbf{u}^{\mathrm{R}}=\mathbf{u}_{\mathrm{T}}+\boldsymbol{\theta} \times\left(\mathbf{r}-\mathbf{r}_{\mathrm{T}}\right),
$$

missä

$$
\mathbf{u}_{\mathrm{T}}(x)=u_{\mathrm{T}}(x) \mathbf{i}+v_{\mathrm{T}}(x) \mathbf{j}+w_{\mathrm{T}}(x) \mathbf{k}
$$

on siirtopisteen siirtymävektori,

$$
\boldsymbol{\theta}(x)=\theta_{x}(x) \mathbf{i}-\theta_{y}(x) \mathbf{j}+\theta_{z}(x) \mathbf{k}
$$

poikkileikkauksen rotaatiovektori,

$$
\mathbf{r}=x \mathbf{i}+y \mathbf{j}+z \mathbf{k}
$$

poikkileikkauksen yleisen pisteen paikkavektori ja

$$
\mathbf{r}_{\mathrm{T}}=x \mathbf{i}+y_{\mathrm{T}} \mathbf{j}+z_{\mathrm{T}} \mathbf{k}
$$

siirtopisteen paikkavektori. Rotaatiovektorin komponentin $\theta_{y}$ positiivinen suunta on valittu palkkiteoriassa usein käytettyyn tapaan $y$-akselin negatiiviseen suuntaan. (Valinnan seurauksena tämän artikkelin esitys muodostuu merkinnällisesti mahdollisimman selkeäksi siten, että johdettavien kaavojen $x, y-$ ja $x, z$-tasoissa tapahtuvaan taivutukseen liittyvät osuudet tulevat olemaan samanmuotoiset.) Siirtymävektorille $\mathbf{u}^{\mathrm{R}}$ saadaan

$$
\begin{aligned}
\mathbf{u}^{\mathrm{R}} & =u_{\mathrm{T}} \mathbf{i}+v_{\mathrm{T}} \mathbf{j}+w_{\mathrm{T}} \mathbf{k}+\left|\begin{array}{ccc}
\mathbf{i} & \mathbf{j} & \mathbf{k} \\
\theta_{x} & -\theta_{y} & \theta_{z} \\
0 & y-y_{\mathrm{T}} & z-z_{\mathrm{T}}
\end{array}\right| \\
& =u_{\mathrm{T}} \mathbf{i}+v_{\mathrm{T}} \mathbf{j}+w_{\mathrm{T}} \mathbf{k}+\left|\begin{array}{cc}
-\theta_{y} & \theta_{z} \\
y-y_{\mathrm{T}} & z-z_{\mathrm{T}}
\end{array}\right| \mathbf{i}+\left|\begin{array}{cc}
\theta_{z} & \theta_{x} \\
z-z_{\mathrm{T}} & 0
\end{array}\right| \mathbf{j}+\left|\begin{array}{cc}
\theta_{x} & -\theta_{y} \\
0 & y-y_{\mathrm{T}}
\end{array}\right| \mathbf{k} \\
& =\left[u_{\mathrm{T}}-\theta_{y}\left(z-z_{\mathrm{T}}\right)-\theta_{z}\left(y-y_{\mathrm{T}}\right)\right] \mathbf{i}+\left[v_{\mathrm{T}}-\theta_{x}\left(z-z_{\mathrm{T}}\right)\right] \mathbf{j}+\left[w_{\mathrm{T}}+\theta_{x}\left(y-y_{\mathrm{T}}\right)\right] \mathbf{k} .
\end{aligned}
$$

Vertaamalla lausekkeita (A.1) ja (A.6) saadaan siirtymäkomponenteille

$$
\begin{aligned}
& u_{x}^{\mathrm{R}}(x, y, z)=u_{\mathrm{T}}(x)-\theta_{z}(x)\left(y-y_{\mathrm{T}}\right)-\theta_{y}(x)\left(z-z_{\mathrm{T}}\right), \\
& u_{y}^{\mathrm{R}}(x, y, z)=v_{\mathrm{T}}(x)-\theta_{x}(x)\left(z-z_{\mathrm{T}}\right), \\
& u_{z}^{\mathrm{R}}(x, y, z)=w_{\mathrm{T}}(x)+\theta_{x}(x)\left(y-y_{\mathrm{T}}\right) .
\end{aligned}
$$

Nämä ovat kaavat (6).

Liite B: Käyristymisfunktioiden yhteyksien (16) johto

Vertaamalla liukumien lausekkeita kaavoissa (13) ja (15) saadaan yhtälöt

$$
\begin{aligned}
& \theta_{x}^{\prime}\left(\frac{\partial \phi}{\partial y}+z_{\mathrm{T}}-\frac{\partial \Phi}{\partial y}\right)+\theta_{x}^{\prime \prime \prime}\left(\frac{\partial \psi_{x}}{\partial y}-\frac{\partial \Psi_{x}}{\partial y}\right)+\gamma_{y}-\theta_{z}^{\prime \prime}\left(\frac{\partial \psi_{y}}{\partial y}-\frac{\partial \Psi_{y}}{\partial y}\right)-\theta_{y}^{\prime \prime}\left(\frac{\partial \psi_{z}}{\partial y}-\frac{\partial \Psi_{z}}{\partial y}\right)=0, \\
& \theta_{x}^{\prime}\left(\frac{\partial \phi}{\partial z}-y_{\mathrm{T}}-\frac{\partial \Phi}{\partial z}\right)+\theta_{x}^{\prime \prime \prime}\left(\frac{\partial \psi_{x}}{\partial z}-\frac{\partial \Psi_{x}}{\partial z}\right)+\gamma_{z}-\theta_{z}^{\prime \prime}\left(\frac{\partial \psi_{y}}{\partial z}-\frac{\partial \Psi_{y}}{\partial z}\right)-\theta_{y}^{\prime \prime}\left(\frac{\partial \psi_{z}}{\partial z}-\frac{\partial \Psi_{z}}{\partial z}\right)=0 .
\end{aligned}
$$

Soveltamalla yhteyksiä (17) saadaan edelleen 


$$
\begin{aligned}
& \theta_{x}^{\prime}\left(\frac{\partial \phi}{\partial y}-\frac{\partial \Phi}{\partial y}+z_{\mathrm{T}}\right)+\theta_{x}^{\prime \prime \prime}\left(\frac{\partial \psi_{x}}{\partial y}-\frac{\partial \Psi_{x}}{\partial y}\right)-\theta_{z}^{\prime \prime}\left(\frac{\partial \psi_{y}}{\partial y}-\frac{\partial \Psi_{y}}{\partial y}+c_{11}\right)-\theta_{y}^{\prime \prime}\left(\frac{\partial \psi_{z}}{\partial y}-\frac{\partial \Psi_{z}}{\partial y}+c_{12}\right)=0 \\
& \theta_{x}^{\prime}\left(\frac{\partial \phi}{\partial z}-\frac{\partial \Phi}{\partial z}-y_{\mathrm{T}}\right)+\theta_{x}^{\prime \prime \prime}\left(\frac{\partial \psi_{x}}{\partial z}-\frac{\partial \Psi_{x}}{\partial z}\right)-\theta_{z}^{\prime \prime}\left(\frac{\partial \psi_{y}}{\partial z}-\frac{\partial \Psi_{y}}{\partial z}+c_{21}\right)-\theta_{y}^{\prime \prime}\left(\frac{\partial \psi_{z}}{\partial z}-\frac{\partial \Psi_{z}}{\partial z}+c_{22}\right)=0 .
\end{aligned}
$$

Koska yhtälöiden (B.2) tulee olla voimassa kaikilla arvoilla $\theta_{x}^{\prime}, \theta_{x}^{\prime \prime \prime}, \theta_{y}^{\prime \prime}$ ja $\theta_{z}^{\prime \prime}$, saadaan käyristymisfunktioden välille differentiaaliyhtälöparit

$$
\begin{aligned}
& \frac{\partial \phi}{\partial y}=\frac{\partial \Phi}{\partial y}-z_{\mathrm{T}}, \frac{\partial \phi}{\partial z}=\frac{\partial \Phi}{\partial z}+y_{\mathrm{T}}, \\
& \frac{\partial \psi_{x}}{\partial y}=\frac{\partial \Psi_{x}}{\partial y}, \frac{\partial \psi_{x}}{\partial z}=\frac{\partial \Psi_{x}}{\partial z}, \\
& \frac{\partial \psi_{y}}{\partial y}=\frac{\partial \Psi_{y}}{\partial y}-c_{11}, \frac{\partial \psi_{y}}{\partial z}=\frac{\partial \Psi_{y}}{\partial z}-c_{21}, \\
& \frac{\partial \psi_{z}}{\partial y}=\frac{\partial \Psi_{z}}{\partial y}-c_{12}, \frac{\partial \psi_{z}}{\partial z}=\frac{\partial \Psi_{z}}{\partial z}-c_{22} .
\end{aligned}
$$

Näiden ratkaisuna saadaan alkuperäisten ja muunnettujen käyristymisfunktioiden välille yhtälöt

$$
\begin{aligned}
& \phi(y, z)=\Phi(y, z)+\Delta_{\Phi}-z_{\mathrm{T}} y+y_{\mathrm{T}} z, \\
& \psi_{x}(y, z)=\Psi_{x}(y, z)+\Delta_{\Psi_{x}}, \\
& \psi_{y}(y, z)=\Psi_{y}(y, z)+\Delta_{\Psi_{y}}-c_{11} y-c_{21} z, \\
& \psi_{z}(y, z)=\Psi_{z}(y, z)+\Delta_{\Psi_{z}}-c_{12} y-c_{22} z .
\end{aligned}
$$

Nämä ovat kaavat (16).

Liite C: Kaavan (17) johto

Vertaamalla leikkausvoimien lausekkeita (55) ja (60) saadaan yhtälö

$$
-\left[\begin{array}{cc}
E I_{z} & E I_{y z} \\
E I_{y z} & E I_{y}
\end{array}\right]\left\{\begin{array}{l}
\theta_{z}^{\prime \prime} \\
\theta_{y}^{\prime \prime}
\end{array}\right\}=G A\left[\begin{array}{cc}
k_{y} & k_{y z} \\
k_{z y} & k_{z}
\end{array}\right]\left\{\begin{array}{l}
\gamma_{y} \\
\gamma_{z}
\end{array}\right\},
$$

josta seuraa

$$
\left\{\begin{array}{l}
\gamma_{y} \\
\gamma_{z}
\end{array}\right\}=-\frac{1}{G A}\left[\begin{array}{cc}
k_{y} & k_{y z} \\
k_{z y} & k_{z}
\end{array}\right]^{-1}\left[\begin{array}{cc}
E I_{z} & E I_{y z} \\
E I_{y z} & E I_{y}
\end{array}\right]\left\{\begin{array}{c}
\theta_{z}^{\prime \prime} \\
\theta_{y}^{\prime \prime}
\end{array}\right\} .
$$

Havaitaan, että kysymyksessä on kaava (17), jossa

$$
\left[\begin{array}{ll}
c_{11} & c_{12} \\
c_{21} & c_{22}
\end{array}\right]=\frac{1}{G A}\left[\begin{array}{ll}
k_{y} & k_{y z} \\
k_{z y} & k_{z}
\end{array}\right]^{-1}\left[\begin{array}{cc}
E I_{z} & E I_{y z} \\
E I_{y z} & E I_{y}
\end{array}\right] .
$$

Liite D: Reuna-arvoprobleemien (21) heikot muodot

Kertomalla kenttäyhtälö (21a) puolittain testifunktiolla $\hat{\Phi}(y, z)$ ja integroimalla määrittelyalueen $A$ yli saadaan 


$$
\int_{A} \hat{\Phi}\left\{\frac{\partial}{\partial y}\left[G\left(\frac{\partial \Phi}{\partial y}-z\right)\right]+\frac{\partial}{\partial z}\left[G\left(\frac{\partial \Phi}{\partial z}+y\right)\right]\right\} \mathrm{d} A=0 .
$$

Soveltamalla osittaisintegrointia saadaan edelleen

$$
\int_{s} \hat{\Phi}\left[n_{y} G\left(\frac{\partial \Phi}{\partial y}-z\right)+n_{z} G\left(\frac{\partial \Phi}{\partial z}+y\right)\right] \mathrm{d} s-\int_{A} G\left[\frac{\partial \hat{\Phi}}{\partial y}\left(\frac{\partial \Phi}{\partial y}-z\right)+\frac{\partial \hat{\Phi}}{\partial z}\left(\frac{\partial \Phi}{\partial z}+y\right)\right] \mathrm{d} A=0
$$

ja ottamalla huomioon reunaehto (21a) lopuksi

$$
\int_{A} G\left[\frac{\partial \hat{\Phi}}{\partial y}\left(\frac{\partial \Phi}{\partial y}-z\right)+\frac{\partial \hat{\Phi}}{\partial z}\left(\frac{\partial \Phi}{\partial z}+y\right)\right] \mathrm{d} A=0
$$

Tämä on heikko muoto (22a). Kertomalla kenttäyhtälö (21b) puolittain testifunktiolla $\hat{\Psi}_{x}(y, z)$ ja integroimalla määrittelyalueen $A$ yli saadaan

$$
\int_{A} \hat{\Psi}_{x}\left[\frac{\partial}{\partial y}\left(G \frac{\partial \Psi_{x}}{\partial y}\right)+\frac{\partial}{\partial z}\left(G \frac{\partial \Psi_{x}}{\partial z}\right)+E \phi\right] \mathrm{d} A=0,
$$

Soveltamalla osittaisintegrointia saadaan edelleen

$$
\int_{s} \hat{\Psi}_{x}\left(n_{y} G \frac{\partial \Psi_{x}}{\partial y}+n_{z} G \frac{\partial \Psi_{x}}{\partial z}\right) \mathrm{d} s-\int_{A} G\left(\frac{\partial \hat{\Psi}_{x}}{\partial y} \frac{\partial \Psi_{x}}{\partial y}+\frac{\partial \hat{\Psi}_{x}}{\partial z} \frac{\partial \Psi_{x}}{\partial z}\right) \mathrm{d} A+\int_{A} E \hat{\Psi}_{x} \phi \mathrm{d} A=0,
$$

ja ottamalla huomioon reunaehto (21b) lopuksi

$$
\int_{A} G\left(\frac{\partial \hat{\Psi}_{x}}{\partial y} \frac{\partial \Psi_{x}}{\partial y}+\frac{\partial \hat{\Psi}_{x}}{\partial z} \frac{\partial \Psi_{x}}{\partial z}\right) \mathrm{d} A=\int_{A} E \hat{\Psi}_{x} \phi \mathrm{d} A
$$

Tämä on heikko muoto (22b). Vastaavaan tapaan menetellen saadaan myös reuna-arvoprobleemien (21c) ja (21d) heikot muodot (22c) ja (22d).

Liite E: Kaavan (74) johto

Kaavassa (73) vääntökulman derivaatan $\theta_{x}^{\prime}$ kertoimena olevalle lausekkeelle saadaan

$$
\begin{aligned}
& \int_{A} G\left[-\left(\frac{\partial \Phi}{\partial y}-z\right)\left(z-z_{\mathrm{T}}\right)+\left(\frac{\partial \Phi}{\partial z}+y\right)\left(y-y_{\mathrm{T}}\right)\right] \mathrm{d} A \\
& =\int_{A} G\left[-\left(\frac{\partial \Phi}{\partial y}-z\right) z+\left(\frac{\partial \Phi}{\partial z}+y\right) y\right] \mathrm{d} A+z_{\mathrm{T}} \int_{A} G\left(\frac{\partial \Phi}{\partial y}-z\right) \mathrm{d} A+y_{\mathrm{T}} \int_{A} G\left(\frac{\partial \Phi}{\partial z}+y\right) \mathrm{d} A \\
& =\int_{A} G\left[-\left(\frac{\partial \Phi}{\partial y}-z\right) z+\left(\frac{\partial \Phi}{\partial z}+y\right) y\right] \mathrm{d} A=G J
\end{aligned}
$$

Lopussa sovellettiin heikkoa muotoa (22a), jossa erityisesti $\hat{\Phi}=y$ ja $\hat{\Phi}=z$. Kaavassa (73) vääntökulman kolmannen derivaatan $\theta_{x}^{\prime \prime \prime}$ kertoimena olevalle lausekkeelle saadaan

$$
\begin{aligned}
& \int_{A} G\left[-\frac{\partial \Psi_{x}}{\partial y}\left(z-z_{\mathrm{T}}\right)+\frac{\partial \Psi_{x}}{\partial z}\left(y-y_{\mathrm{T}}\right)\right] \mathrm{d} A \\
& =\int_{A} G\left[\frac{\partial \Psi_{x}}{\partial y}\left(\frac{\partial \phi}{\partial y}-z+z_{\mathrm{T}}\right)+\frac{\partial \Psi_{x}}{\partial z}\left(\frac{\partial \phi}{\partial z}+y-y_{\mathrm{T}}\right)\right] \mathrm{d} A-\int_{A} G\left(\frac{\partial \phi}{\partial y} \frac{\partial \Psi_{x}}{\partial y}+\frac{\partial \phi}{\partial z} \frac{\partial \Psi_{x}}{\partial z}\right) \mathrm{d} A \\
& =\int_{A} G\left[\frac{\partial \Psi_{x}}{\partial y}\left(\frac{\partial \Phi}{\partial y}-z\right)+\frac{\partial \Psi_{x}}{\partial z}\left(\frac{\partial \Phi}{\partial z}+y\right)\right] \mathrm{d} A-\int_{A} G\left(\frac{\partial \phi}{\partial y} \frac{\partial \Psi_{x}}{\partial y}+\frac{\partial \phi}{\partial z} \frac{\partial \Psi_{x}}{\partial z}\right) \mathrm{d} A \\
& =-\int_{A} E \phi^{2} \mathrm{~d} A=-E I_{\phi} .
\end{aligned}
$$


Aluksi lisättiin ja vähennettiin lauseke

$$
\int_{A} G\left(\frac{\partial \phi}{\partial y} \frac{\partial \Psi_{x}}{\partial y}+\frac{\partial \phi}{\partial z} \frac{\partial \Psi_{x}}{\partial z}\right) \mathrm{d} A
$$

sitten käytettiin kaavaa (16a) ja lopuksi sovellettiin reuna-arvoprobleemien heikkoja muotoja (22a) ja (22b), joissa erityisesti $\hat{\Phi}=\Psi_{x}$ ja $\hat{\Psi}_{x}=\phi$. Kaavassa (73) kiertymän toisen derivaatan $\theta_{z}^{\prime \prime}$ kertoimena olevalle lausekkeelle saadaan

$$
\begin{aligned}
& \int_{A} G\left[-\frac{\partial \Psi_{y}}{\partial y}\left(z-z_{\mathrm{T}}\right)+\frac{\partial \Psi_{y}}{\partial z}\left(y-y_{\mathrm{T}}\right)\right] \mathrm{d} A \\
& =\int_{A} G\left[\frac{\partial \Psi_{y}}{\partial y}\left(\frac{\partial \Phi}{\partial y}-z\right)+\frac{\partial \Psi_{y}}{\partial z}\left(\frac{\partial \Phi}{\partial z}+y\right)\right] \mathrm{d} A-\int_{A} G\left(\frac{\partial \phi}{\partial y} \frac{\partial \Psi_{y}}{\partial y}+\frac{\partial \phi}{\partial z} \frac{\partial \Psi_{y}}{\partial z}\right) \mathrm{d} A \\
& =-\int_{A} E \phi y \mathrm{~d} A=-E I_{z \phi}=0 .
\end{aligned}
$$

Aluksi lisättiin ja vähennettiin lauseke

$$
\int_{A} G\left(\frac{\partial \phi}{\partial y} \frac{\partial \Psi_{y}}{\partial y}+\frac{\partial \phi}{\partial z} \frac{\partial \Psi_{y}}{\partial z}\right) \mathrm{d} A,
$$

sitten käytettiin kaavaa (16a) ja lopuksi sovellettiin reuna-arvoprobleemien heikkoja muotoja (22a) ja (22b), joissa erityisesti $\Phi=\Psi_{y}$ ja $\hat{\Psi}_{y}=\phi$. Vastaavalla tavalla saadaan johdetuksi kaavassa (73) kiertymän toisen derivaatan $\theta_{y}^{\prime \prime}$ kertoimena olevalle lausekkeelle tulos

$$
\int_{A} G\left[-\frac{\partial \Psi_{z}}{\partial y}\left(z-z_{\mathrm{T}}\right)+\frac{\partial \Psi_{z}}{\partial z}\left(y-y_{\mathrm{T}}\right)\right] \mathrm{d} A=-E I_{y \phi}=0
$$

Sijoittamalla tulokset (E.1), (E.2), (E.3) ja (E.4) kaavaan (73) saadaan kaava (74).

Liite F: Avointen ohutseinämäisten sauvojen vääntöön liittyviä kaavoja

Tarkastellaan avointa ohutseinämäistä poikkileikkausta, jonka keskiviivaa seuraa kaarenpituuskoordinaatti s. Keskiviivan yhtälöt ovat

$$
y=y(s), \quad z=z(s)
$$

ja poikkileikkauksen paksuus on $t(s)$. Rajoitutaan yksinkertaisuuden vuoksi haarautumattomaan poikkileikkaukseen, jonka toinen pää on pisteessä $s=0$ ja toinen pää pisteessä $s=l$. Poikkileikkausen sektoriaalinen koordinaatti $\Omega_{\mathrm{A}}(s)$ pisteen $\mathrm{A}:\left(y_{\mathrm{A}}, z_{\mathrm{A}}\right)$ suhteen voidaan määrittää kaavalla

$$
\Omega_{\mathrm{A}}(s)=\int_{s_{0}}^{s}\left\{\left[y\left(s^{\prime}\right)-y_{\mathrm{A}}\right] \frac{\mathrm{d} z}{\mathrm{~d} s}\left(s^{\prime}\right)-\left[z\left(s^{\prime}\right)-z_{\mathrm{A}}\right] \frac{\mathrm{d} y}{\mathrm{~d} s}\left(s^{\prime}\right)\right\} \mathrm{d} s^{\prime} .
$$

Pistettä A kutsutaan sektoriaalisen koordinaatin navaksi ja pistettä $\mathrm{P}_{0}: s_{0}$, jossa $\Omega_{\mathrm{A}}$ häviää, sen nollapisteeksi. Kun sektoriaalinen koordinaatti pisteen A suhteen tunnetaan, voidaan sektoriaalinen koordinaatti pisteen $B$ suhteen määrittää napapisteen vaihtokaavalla

$$
\Omega_{\mathrm{B}}=\Omega_{\mathrm{A}}+\left(z_{\mathrm{B}}-z_{\mathrm{A}}\right)\left(y-y_{0}\right)-\left(y_{\mathrm{B}}-y_{\mathrm{A}}\right)\left(z-z_{0}\right),
$$

missä $y_{0}$ ja $z_{0}$ ovat nollapisteen $\mathrm{P}_{0}$ koordinaatit.

Poikkileikkaukselle, jonka sektoriaalinen koordinaatti on $\Omega$, määritellään sektoriaalinen staattinen momentti, sektoriaaliset tulomomentit ja sektoriaalinen neliömomentti kaavoilla 


$$
\begin{aligned}
& S_{\Omega}=\int_{A} \Omega \mathrm{d} A=\int_{0}^{l} \Omega(s) t(s) \mathrm{d} s, \\
& I_{y \Omega}=\int_{A} z \Omega \mathrm{d} A=\int_{0}^{l} z(s) \Omega(s) t(s) \mathrm{d} s, \quad I_{z \Omega}=\int_{A} y \Omega \mathrm{d} A=\int_{0}^{l} y(s) \Omega(s) t(s) \mathrm{d} s, \\
& I_{\Omega}=\int_{A} \Omega^{2} \mathrm{~d} A=\int_{0}^{l} \Omega^{2}(s) t(s) \mathrm{d} s .
\end{aligned}
$$

Lisäksi määritellään osapoikkileikkauksen sektoriaalinen staattinen momentti kaavalla

$$
\tilde{S}_{\Omega}(s)=\int_{s}^{l} \Omega\left(s^{\prime}\right) t\left(s^{\prime}\right) \mathrm{d} s^{\prime} .
$$

Sektoriaalista koordinaattia $\omega(s)$, jolle on voimassa ehto $S_{\omega}=0$, kutsutaan normeeratuksi. Sille voidaan johtaa ([4], kaava (5.27)) kaava

$$
\omega(s)=\Omega(s)-\frac{S_{\Omega}}{A} .
$$

Oletetaan, että $\Omega_{\mathrm{O}}(s)$ on sektoriaalinen koordinaatti origon O suhteen, jonka nollapiste on $\mathrm{P}_{0}$, tunnetaan. Kaavan (F.3) perusteella saadaan sektoriaaliselle koordinaatille $\Omega_{\mathrm{T}}(\mathrm{s})$ vääntökeskiön $\mathrm{T}$ suhteen lauseke

$$
\Omega_{\mathrm{T}}=\Omega_{\mathrm{O}}+z_{\mathrm{T}} y-y_{\mathrm{T}} z-z_{\mathrm{T}} y_{0}+y_{\mathrm{T}} z_{0} .
$$

Normeeratulle sektoriaaliselle koordinaatille $\omega_{\mathrm{T}}(s)$ vääntökeskiön suhteen saadaan soveltamalla kaavoja (F.6) ja (F.7)

$$
\omega_{\mathrm{T}}=\Omega_{\mathrm{O}}+z_{\mathrm{T}} y-y_{\mathrm{T}} z-\frac{S_{\Omega_{\mathrm{O}}}+z_{\mathrm{T}} S_{z}-y_{\mathrm{T}} S_{y}}{A} .
$$

Kun origo on asetettu tavanomaisesti pintakeskiöön, jolloin $S_{z}=0$ ja $S_{y}=0$, seuraa tästä

$$
\omega_{\mathrm{T}}=\Omega_{\mathrm{O}}+\Delta_{\Omega}+z_{\mathrm{T}} y-y_{\mathrm{T}} z
$$

missä

$$
\Delta_{\Omega}=-\frac{S_{\Omega_{\mathrm{O}}}}{A} .
$$

Avoimen ohutseinämäisen poikkileikkauksen vääntökeskiö $\mathrm{T}$ määritellään pisteenä, jonka suhteen määritetyn sektoriaalisen koordinaatin $\Omega_{\mathrm{T}}$ avulla määritetyilla tulomomenteille on voimassa ehdot $I_{y \Omega}=0$ ja $I_{z \Omega}=0$. Näiden ehtojen perusteella vääntökeskiön koordinaateille voidaan johtaa ([4] kaava (5.39)) kaava

$$
\left\{\begin{array}{l}
y_{\mathrm{T}} \\
z_{\mathrm{T}}
\end{array}\right\}=\frac{1}{I_{y} I_{z}-I_{y z}^{2}}\left[\begin{array}{cc}
I_{z} & I_{y z} \\
I_{y z} & I_{y}
\end{array}\right]\left\{\begin{array}{c}
I_{y \Omega_{\mathrm{O}}} \\
-I_{z \Omega_{\mathrm{O}}}
\end{array}\right\} .
$$

Kun sektoriaalinen koordinaatti $\Omega_{\mathrm{O}}(s)$ origon $\mathrm{O}$ suhteen, jonka nollapiste on $\mathrm{P}_{0}$, tunnetaan, voidaan vääntökeskiön koordinaatit $y_{\mathrm{T}}$ ja $z_{\mathrm{T}}$ määrittää kaavalla (F.11) ja normeerattu sektoriaalinen koordinaatti $\omega_{\mathrm{T}}(s)$ vääntökeskiön T suhteen kaavalla (F.9).

Erityinen avointen ohutseinämäisen sauvojen vääntöteorian jännitysresultantti on bimomentti. Se määritellään kaavalla 


$$
B=\int_{A} \sigma_{x} \omega_{\mathrm{T}} \mathrm{d} A=\int_{0}^{l} \sigma_{x}(s) \omega_{\mathrm{T}}(s) t(s) \mathrm{d} s .
$$

Avointen ohutseinämäisen sauvojen yhdistetyssä taivutus- ja vääntöteoriassa, kun $y, z-$ koordinaatisto yhtyy poikkileikkauksen pääjäyhyyskoordinaatistoon ( $I_{y z}=0$ ), normaalijännitykselle ja keskimääräiselle leikkausjännitykselle on voimassa kaavat

$$
\begin{gathered}
\sigma_{x}(s)=\frac{N}{A}+\frac{M_{z}}{I_{z}} y(s)+\frac{M_{y}}{I_{y}} z(s)-\frac{B}{I_{\omega}} \omega(s), \\
\bar{\tau}_{s X}(s)=\frac{Q_{y}}{I_{z}} \frac{\tilde{S}_{z}(s)}{t(s)}+\frac{Q_{z}}{I_{y}} \frac{\tilde{S}_{y}(s)}{t(s)}-\frac{B^{\prime}}{I_{\omega}} \frac{\tilde{S}_{\omega}(s)}{t(s)} .
\end{gathered}
$$

Kaavassa (F.14) $\tilde{S}_{z}(s)$ ja $\tilde{S}_{y}(s)$ ovat osapoikkileikkauksen staattiset momenetit, jotka määritetään vastaavaan tapaan kuin osapoikkileikkauksen sektoriaalinen staattinen momentti $\tilde{S}_{\omega}(s)$ kaavassa (F.5). Kaava (F.14) ei sisällä Saint-Venantin väännön osuutta leikkausjännityksestä $\tau_{s X}$. Se on totuttu määrittämään erikseen likikaavalla

$$
\tau_{s X}=2 \frac{T}{J} \eta
$$

missä $\eta$ on poikkileikkauksen keskiviivaa $S$ vastaan kohtisuora koordinaatti ja

$$
J=\frac{1}{3} \int_{0}^{l} t^{3}(s) \mathrm{d} s
$$

on avoimen ohutseinämäisen poikkileikkauksen vääntöjäyhyysmomentti.

\section{Viitteet}

[1] J. Aalto and R. Syrjä, “A unified solution attempt for the torsion problem”, Proceedings of the $24^{\text {th }}$ Nordic Seminar on Computational Mechanics, J. Freund and R. Kouhia (Eds.), Aalto University, 2011.

[2] J. Aalto ja E.-M. Salonen, “Systemaattinen menettelytapa taivutetun ja väännetyn palkin jännitysten määrittämiseksi”, Proceedings of the $11^{\text {th }}$ Finnish Mechanics Days, H. Koivurova and M. Malaska (Eds.), University of Oulu 2012.

[3] S.P. Timoshenko and J. N. Goodier, “Theory of Elasticity”, $3^{\text {rd }}$ ed., McGraw-Hill, 1970.

[4] C.F. Kollbrunner and K. Basler, “Torsion in Structures”, Springer-Verlag, 1969.

[5] S.P. Timoshenko, "On the correction factor for shear of the differential equation for transverse vibrations of bars of uniform cross-section.”, Philosophical Magazine, p. 744, 1921.

Jukka Aalto, Aalto-yliopisto, Insinööritieteiden korkeakoulu, Rakennustekniikan laitos PL 12100, 00076 Aalto jukka.aalto@aalto.fi 